\title{
Molecular dynamics simulations of cesium adsorption on illite nanoparticles
}

Laura N. Lammers ${ }^{\mathrm{a}, \mathrm{b}}$ *, Ian C. Bourg ${ }^{\mathrm{a}, \mathrm{c}}$, Masahiko Okumura ${ }^{\mathrm{d}}$, Kedarnath Kolluri ${ }^{\mathrm{a}, \mathrm{b}}$, Garrison Sposito ${ }^{\mathrm{b}}$, Masahiko Machida ${ }^{\mathrm{d}}$

${ }^{a}$ Earth and Environmental Sciences Area, Lawrence Berkeley National Laboratory, Berkeley, USA.

${ }^{\mathrm{b}}$ Department of Environmental Science, Policy, and Management (ESPM), University of California, Berkeley, USA. lnlammers@ berkeley.edu, gsposito@ berkeley.edu.

${ }^{\mathrm{c}}$ Department of Civil and Environmental Engineering (CEE) and Princeton Environmental Institute (PEI), Princeton University, Princeton, USA. bourg@ princeton.edu.

${ }^{\mathrm{d}}$ Center for Computational Science and e-Systems, Japan Atomic Energy Agency, Kashiwa, Japan. okumura.masahiko@jaea.go.jp, machida.masahiko@jaea.go.jp.

*Corresponding author. Email: Inlammers@ berkeley.edu, telephone: 510-664-4210. 


\begin{abstract}
The charged surfaces of micaceous minerals, especially illite, regulate the mobility of the major radioisotopes of $\mathrm{Cs}\left({ }^{134} \mathrm{Cs},{ }^{135} \mathrm{Cs},{ }^{137} \mathrm{Cs}\right)$ in the geosphere. Despite the long history of Cs adsorption studies, the nature of the illite surface sites remains incompletely understood. To address this problem, we present atomistic simulations of Cs competition with $\mathrm{Na}$ for three candidate illite adsorption sites - edge, basal plane, and interlayer. Our simulation results are broadly consistent with affinities and selectivities that have been inferred from surface complexation models. Cation exchange on the basal planes is thermodynamically ideal, but exchange on edge surfaces and within interlayers shows complex, thermodynamically non-ideal behavior. The basal planes are weakly Csselective, while edges and interlayers have much higher affinity for Cs. The dynamics of $\mathrm{Na}-\mathrm{Cs}$ exchange are rapid for both cations on the basal planes, but considerably slower for Cs localized on edge surfaces. In addition to new insights into Cs adsorption and exchange with $\mathrm{Na}$ on illite, we report the development of a methodology capable of simulating fully-flexible clay mineral nanoparticles with stable edge surfaces using a well-tested interatomic potential model.
\end{abstract}

Keywords: Radiocesium; Molecular Dynamics Simulations; Geochemistry

\title{
1. INTRODUCTION
}

Any future reliance on nuclear energy to play a major role in lessening our dependence on fossil fuels brings with it a need to address the potential for long-term environmental contamination by radioisotopes (Pacala and Socolow, 2004). Two isotopes of cesium, ${ }^{135} \mathrm{Cs}$ and ${ }^{137} \mathrm{Cs}$, are among the most important contaminants associated with the nuclear fuel cycle because of their high fission yield, long half lives $\left(2.3 \times 10^{6}\right.$ and 30 a, respectively), high solubility in water, and metabolic similarity to potassium. These radioisotopes are key concerns in the geologic storage of radioactive waste (McCombie, 1997; Gaboreau et al., 2012; Chen et al., 2014), the management of legacy sites contaminated during the development of nuclear power (Evans et al., 1983; Olsen et al., 
1986), and the remediation of soils contaminated by catastrophic releases such as those that occurred at the Chernobyl and Fukushima Daiichi nuclear power plants (FilipovicVincekovic, 1991; Yasunari et al., 2011; Yoshida and Kanda, 2012). In the Fukushima region, in particular, ${ }^{137} \mathrm{Cs}$ is the main source of external radiation dose five years after the nuclear disaster of March 2011. The most important process controlling the solubility and mobility of cesium in soils, sediments, and sedimentary rocks is the formation of strong surface complexes with clay minerals (Anderson and Sposito, 1991) and particularly with the micaceous minerals, illite, vermiculite, and mica (Evans et al., 1983; Hinton et al., 2006; Bourg and Sposito, 2011a; Mukai et al., 2014; Nakao et al., 2014). Cesium adsorption on illite is of particular importance in the geologic storage of radioactive waste, because illite often dominates the mineralogy of fine-grained sedimentary rocks considered for use as host formations (Tachi et al., 2011; Gaboreau et al., 2012; Chen et al., 2014).

Studies of the adsorption of Cs by illite have a long history (Tamura, 1961; Sawhney, 1972; Eberl, 1980; Brouwer et al., 1983; Comans and Hockley, 1992; Smith and Comans, 1996; Staunton and Roubaud, 1997; Poinssot et al., 1999; Rajec et al., 1999; Bradbury and Baeyens, 2000; McKinley et al., 2001, 2004; Bostick et al., 2002; Zachara et al., 2002; Liu et al., 2003; Baeyens and Bradbury, 2004; de Koning and Comans, 2004; Bergaoui et al., 2005; Turner et al., 2006). Recent efforts have deployed a combination of wet chemistry experiments (Wampler et al., 2012; Benedicto et al., 2014; Dzene et al., 2015), high-resolution imaging (Kogure et al., 2012; Mukai et al., 2014; Tamura et al., 2014; Fuller et al., 2015), synchrotron X-ray spectroscopy (Fan et al., 2014; Honda et al., 2016), and atomistic-level simulations (Okumura et al., 2013; Suehara and Yamada, 
2013; Ikeda et al., 2015; Zaunbrecher et al., 2015) to gain detailed insight into Cs adsorption mechanisms, selectivity, and kinetics. The emerging view from these studies is that Cs adsorption involves at least three types of surface sites: basal sites located on the external basal surfaces of illite particles, slow sites located in anhydrous illite interlayers, and high affinity sites of unclear nature. Adsorption on the basal sites is rapid $(<24 \mathrm{hr}$ ), reversible, and weakly selective (Table 1$)$. The slow sites have slow adsorption and desorption kinetics (likely weeks to months) and a higher total capacity than the basal sites. Finally, the high affinity sites have a very small total capacity and a very high affinity for cesium and other weakly hydrated cations $\left(\mathrm{K}^{+}, \mathrm{NH}_{4}{ }^{+}\right)$. The high-affinity sites and slow sites are particularly important, because they control the long-term migration of cesium in the geosphere (Comans et al., 1989; Turner et al., 2006; Shiozawa, 2014).

Despite the importance of the high-affinity and slow sites of illite for cesium fate and transport, important questions remain unanswered regarding the properties of these sites. First, the structure of the high affinity sites is a continuing topic of investigation (Kim and Kirkpatrick, 1998; McKinley et al., 2004; Suehara and Yamada, 2013; Okumura et al., 2013). The predominant hypothesis is that they occur in "wedge" regions where illite or vermiculite interlayers transition from a collapsed state to an expanded state (Chorover et al., 1999; Wampler et al., 2012; Okumura et al., 2013; Zaunbrecher et al., 2015). The existence of these regions is supported by electron microscopy observations showing that weathering induces a discernible "fraying" at the edges of illite and mica crystals (McKinley et al., 2004; Fuller et al., 2015), perhaps associated with the replacement of $\mathrm{K}$ by solvated Ca near the extremities of the anhydrous interlayers (Fuller et al., 2015). Second, the cation exchange kinetics and selectivity of the slow sites remain 
poorly understood, in part because of a lack of long-term adsorption and desorption studies. For example, some studies have hypothesized that basal and slow sites have essentially the same Na-Cs exchange selectivity (Benedicto et al., 2014), whereas atomistic simulations suggest that Cs is much more selectively retained in anhydrous clay interlayers than on external basal surfaces (Rotenberg et al., 2009). The few geochemical modeling studies that described slow sites as distinct surface sites treated them as ideal cation exchangers (Comans and Hockley, 1992; Turner et al., 2006) despite evidence that these sites, at least in some cases, form interstratified structures in which Cs displaces $\mathrm{K}$ in some interlayers but not in others (Okumura et al., 2014). Finally, the adsorptiondesorption kinetics of the slow and high-affinity sites remain incompletely understood. For example, several studies have shown that solution chemistry strongly affects the kinetics of adsorption on slow sites (Benedicto et al., 2014) and desorption from highaffinity sites (de Koning and Comans, 2004), perhaps through a mechanism analogous to the well known salinity-dependence of smectite clay swelling (Slade et al., 1991; Karnland et al., 2007). Geochemical models of cesium adsorption on illite almost invariably ignore the slow sites (Bradbury and Baeyens, 2000; Steefel et al., 2003; Gaboreau et al., 2012; Fuller et al., 2014) or assume that their properties are identical to those of the basal sites (Benedicto et al., 2014) or the high-affinity sites (Turner et al., 2006). The range of values of Na-Cs and K-Cs exchange selectivity coefficients used in surface complexation models is shown in Table 1.

Table 1. Cation exchange selectivities of the high affinity and basal sites used in surface complexation models of Cs adsorption on illite and related minerals. Some models also include an intermediate affinity site of unclear mechanistic basis. The table shows the range of values used in existing models of illite surface chemistry (Brouwer et al., 1983; 
Poinssot et al., 1999; Bradbury and Baeyens, 2000; Steefel et al., 2003; Liu et al., 2004; Turner et al., 2006; Gaucher et al., 2009; Chen et al., 2014; Fuller et al., 2014; Benedicto et al., 2014; Fan et al., 2014). For comparison, values for smectite basal surfaces are shown in the last column as calculated by Bourg and Sposito (2011a) based on previous studies. Cesium exchange selectivity on smectite increases with layer charge (values are reported for smectite layer charges ranging from 0.7 to $1.4 \mathrm{~mol}_{\mathrm{c}} \mathrm{kg}^{-1}$ ). The notation $K_{\mathrm{eq}}{ }^{i / j}$ refers to the equilibrium constant for the replacement of $i$ by $j$ on illite surface sites.

\begin{tabular}{llll} 
Site type & Illite basal site & Illite high affinity site & Smectite basal site \\
\hline \hline $\log K_{\mathrm{eq}}{ }_{\mathrm{Na} / \mathrm{Cs}}$ & 1.6 to 2.0 & 6.6 to 7.2 & 0.7 to 1.7 \\
$\log K_{\mathrm{eq}} \mathrm{K}$ & 0.4 to 1.1 & 4.1 to 5.5 & 0.2 to 1.2 \\
\hline
\end{tabular}

The questions listed above persist in part because the three types of surface sites are challenging to isolate experimentally. For example, spectroscopic or elemental mapping results are challenging to obtain at the very low surface loadings characteristic of the high affinity sites. Atomistic simulation techniques such as molecular dynamics (MD) simulations and density functional theory (DFT) calculations can, in principle, circumvent these difficulties by allowing a direct observation of individual Cs ions on different surface sites. Existing simulation studies have probed cesium adsorption in the interlayer nanopores of swelling clay minerals (Nakano et al., 2003; Teppen and Miller, 2006; Rotenberg et al., 2007, 2009; Bourg and Sposito, 2010; Ikeda et al., 2015), in anhydrous clay interlayers (Rotenberg et al., 2009; Suehara and Yamada, 2013), and at illite and vermiculite wedge sites (Okumura et al., 2013; Zaunbrecher et al., 2015). However, no existing atomistic simulation study has examined cesium adsorption selectivity on different surfaces of a single illite particle, because of two methodological challenges. Ab initio MD (i.e., time-dependent DFT) simulations are limited to timescales up to $\sim 100$ ps that are significantly shorter than the characteristic timescales of Cs migration on hydrated clay surfaces [on the order of nanoseconds (Nakano et al., 2003; 
Bourg and Sposito, 2010)]. Classical MD simulations can probe time-scales up to $~ 100$ ns, but their predictions can be highly sensitive to the choice of inter-atomic potential parameters. The most well-tested inter-atomic potential model for clay-water systems, the CLAYFF model of Cygan et al. (2004), was designed to simulate the basal surfaces of infinite clay particles, and its ability to describe the edge surfaces of clay particles is not well established. In fact, even the detailed microstructure and stoichiometry of clay edge surfaces remains poorly constrained (Carroll and Walther, 1990; Bourg et al., 2007; Newton et al., 2016).

Here, we present the first ever atomistic simulation study of Cs adsorption on three binding sites (basal, edge, and interlayer) of a model illite nanoparticle. To account for the slow migration of Cs near clay surfaces, our simulations used relatively long (50 ns) classical MD simulations in combination with thermodynamic integration calculations (i.e., alchemical transformations wherein short-range interaction potential parameters for $\mathrm{Na}$ are incrementally adjusted to Cs at different sites on the illite surface). In addition to new insights into Cs adsorption on illite, a significant outcome of our study is the development of a methodology capable of simulating fully-flexible illite nanoparticles with stable edge surfaces based on a well-tested interatomic potential model.

\section{Simulation MethodologY}

Atomistic simulations were performed using the molecular dynamics (MD) simulation code LAMMPS, which solves Newton's equations of motion for manyparticle systems interacting through pairwise potentials (Plimpton, 1995). Interatomic 
interactions were described as the sum of Coulomb and dispersive (Lennard-Jones 6-12) interactions using the well-known SPC/E water model (Berendsen et al., 1987), the CLAYFF model of mineral-water interactions (Cygan et al., 2004), and the Smith-Dang parameters for Na, K, Cs, and Cl (Smith and Dang, 1994; Dang, 1995). Interactions between unlike atoms were derived using the Lorentz-Berthelot combining rules. Our choice of force fields has been successfully tested against experimental data on the structure and dynamics of water and ions on basal surfaces of 2:1 clay minerals (Bourg \& Sposito, 2010; Ferrage et al., 2011; Marry et al., 2011; Holmboe \& Bourg, 2014) and on hydroxylated silica and quartz surfaces (Skelton et al., 2011; Bourg \& Steefel, 2012). In the case of clay-water systems, MD simulation studies have focused almost exclusively on the basal surfaces and hydrous interlayer nanopores. Adsorption on clay edge surfaces remains almost entirely unexamined, in part because the CLAYFF model was not parameterized to simulate clay edge surfaces. The few existing MD simulations of clay edges focused on smectite (Rotenberg et al., 2007; Hsiao and Hedström, 2015; Newton et al., 2016; Tournassat et al., 2016) or pyrophyllite (Martins et al., 2014; Newton \& Sposito, 2015) rather than illite. Only three of these studies used fully flexible clay structures (Martins et al., 2014; Newton \& Sposito, 2015; Newton et al., 2016).

\subsection{System setup}

A four-layer illite nanoparticle was constructed using the structural parameters reported in Gualtieri (2000). Edge surfaces were created by cleaving the crystal structure along the so-called AC bond chain identified by periodic bond chain theory (White \& Zelazny, 1988), the most stable or one of the most stable cleavage planes according to 
quantum mechanical calculations (Churakov, 2006; Lavikainen et al., 2015; Kwon \& Newton, 2016). Because of the periodic boundary conditions, the resulting nanoparticle is effectively an infinite needle elongated parallel to the crystallographic b-axis and cleaved along the $\mathrm{AC}$ plane. Isomorphic substitutions of $\mathrm{Si}$ by $\mathrm{Al}$ were distributed randomly throughout the particle according to the chemical formula of illite, $\mathrm{K}_{0.7} \mathrm{Al}_{2}\left(\mathrm{Si}_{3.3} \mathrm{Al}_{0.7}\right) \mathrm{O}_{10}(\mathrm{OH})_{2}$, with the constraint that isomorphic substitutions were not allowed to occur in neighboring tetrahedra (Sainz-Díaz et al., 2001). Charge-balancing K ions were initially distributed randomly in ditrigonal cavity positions in the anhydrous interlayers and on external basal surfaces, with the average occupancy of cavity positions being twice as large in the interlayer as on the external surfaces. The initial potassium ion distribution was later optimized as described in section 2.2. The illite nanoparticle was surrounded by a bath of water molecules and $\mathrm{Na}, \mathrm{Cs}$, and $\mathrm{Cl}$ ions (total of 33,403 atoms).

As noted above, illite edge surfaces were created by cleaving the illite crystal along the so-called AC bond chain. Then, the cleaved edge surfaces were healed by attaching $\mathrm{O}$ atoms to under-coordinated edge metals (Fig. 1). The resulting edge surface carries four distinct types of $\mathrm{O}$ atoms: aluminol $\mathrm{O}$ atoms (Oe3) coordinated to octahedral $\mathrm{Al}$ atoms $\left(\equiv \mathrm{Al}_{\mathrm{O}^{-} \mathrm{O}}\right)$, bridging $\mathrm{O}$ atoms $(\mathrm{Oe} 6)$ coordinated to tetrahedral $\mathrm{Si}$ and octahedral $\mathrm{Al}$ atoms $\left(\equiv \mathrm{Al}_{\mathrm{O}}-\mathrm{O}-\mathrm{Si} \equiv\right)$, and two types of silanol $\mathrm{O}$ atoms (Oe1, Oe2) coordinated to tetrahedral $\mathrm{Si}$ atoms $(\equiv \mathrm{Si}-\mathrm{O})$. The structure also carries three additional types of surface $\mathrm{O}$ atoms resulting from isomorphic substitutions of $\mathrm{Si}$ by $\mathrm{Al}$ atom near Oe1, Oe2, and Oe6 atoms (referred to as $\mathrm{Oe} 4, \mathrm{Oe} 5$, and $\mathrm{Oe} 7$, respectively). Finally, edge $\mathrm{O}$ atoms were protonated in accordance with the expected protonation state at near-neutral $\mathrm{pH}$ conditions. Specifically, Oe1, Oe2, Oe4, and Oe5 atoms were assigned a single proton, 
Oe3 atoms were doubly protonated, and Oe6 and Oe7 atoms were not protonated

(Bickmore et al., 2003; Tournassat et al., 2004; Bourg et al., 2007; Liu et al., 2014). The resulting edge surface has a net proton surface charge of zero.

Figure 1. Schematic view of the illite $\mathrm{AC}$ edge surface before protonation of edge $\mathrm{O}$ atoms. Colors indicate $\mathrm{O}$ (red), $\mathrm{H}$ (pink), $\mathrm{Al}$ (light blue), $\mathrm{Si}$ (dark blue), and $\mathrm{K}$ atoms (purple). In the absence of isomorphic substitutions, the edge surface carries two silanol sites (Oe1, Oe2), one aluminol site (Oe3), and one bridging oxygen (Oe6), as labeled on the figure. Isomorphic substitutions of $\mathrm{Al}$ for $\mathrm{Si}$ near the edge surface give rise to additional types of edge $\mathrm{O}$ atoms, listed in parentheses. Brackets indicate regions of the edge surface referred to hereafter as hanging $(\mathrm{H})$ and indented (I).

The slanted structure of the AC cleavage leads

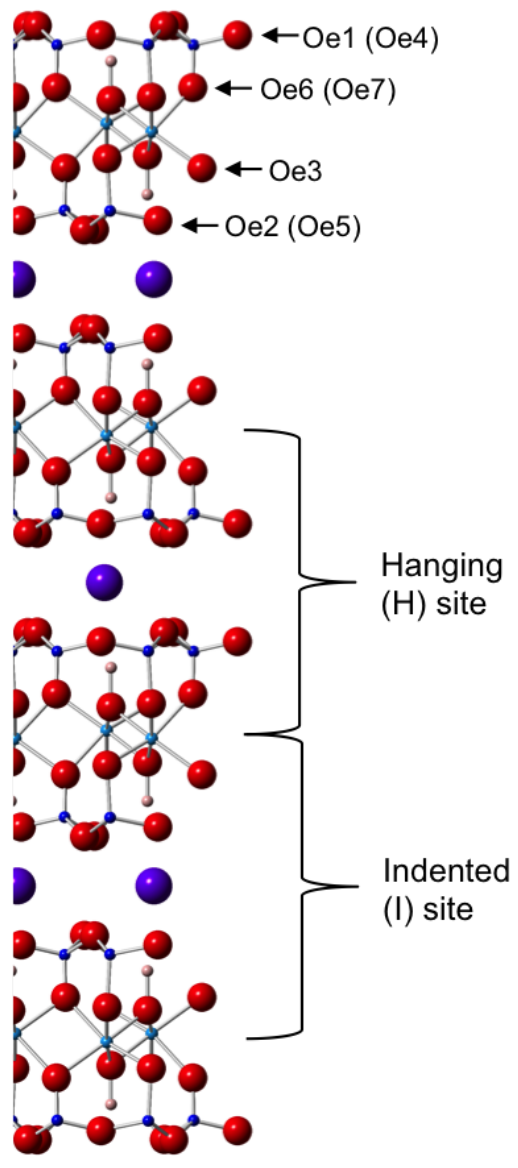
to the formation of two distinct edge sites, which we designate as hanging (H) and indented (I) sites (Fig. 1). Atomic configurations adjacent to these sites differ substantially, leading to the formation of two unique edge-surface coordination environments for adsorbed cations. Our simulations enabled us to distinguish the interactions of these two different sites with aqueous ions $(\mathrm{Na}, \mathrm{Cs}, \mathrm{Cl})$.

The partial charges of several $\mathrm{O}$ atoms on clay edge surfaces (specifically, Oe3, Oe4, Oe5, Oe6, and Oe7) are not defined in the CLAYFF model. Here, we calculated CLAYFF-compatible partial charges 
for edge oxygen atoms based on an algorithm that accounts for bond valence, charge saturation, and cation charge. In this calculation, we assume that the partial charge on edge oxygen atoms depends on the oxygen valence (-2.00 v.u.) balanced by the total effective charge contributed by coordinating cations $i$ :

$Z_{\text {Oej }}^{P}=2.00+\frac{N_{i}\left(Z_{i} Z_{i}^{P}\right)}{C N_{i}}$,

where $Z_{i}$ is the valence of cation $i, Z_{i}^{\mathrm{P}}$ is the partial charge of $i, N_{i}$ is the number of $i$ cations coordinating edge oxygen $j$, and $\mathrm{CN}_{\mathrm{i}}$ represents the total number of $\mathrm{O}$ atoms coordinating cation $i$. This procedure ensures net charge neutrality and captures the expected dependence of the partial charge of edge $\mathrm{O}$ atoms on their degree of over- or under-saturation from a bond-valence perspective (Tournassat et al., 2016). A list of edge oxygen sites, their coordination, and calculated partial charges is provided in Table 2.

Table 2. Partial charges and coordination state of edge $\mathrm{O}$ atoms. Other properties of edge $\mathrm{O}$ atoms are defined by the CLAYFF model. Octahedral and tetrahedral $\mathrm{Al}$ atoms are referred to as $\mathrm{Al}_{\mathrm{O}}$ and $\mathrm{Al}_{\mathrm{T}}$, respectively.

\begin{tabular}{|c|c|c|c|c|c|c|c|c|}
\hline \multirow{2}{*}{$\begin{array}{l}\text { Edge } \\
\text { Site }\end{array}$} & \multirow[b]{2}{*}{ Site Description } & \multirow{2}{*}{$\begin{array}{l}\text { Partial } \\
\text { Charge }\end{array}$} & \multirow[b]{2}{*}{ B.V. } & \multirow{2}{*}{$\begin{array}{c}\text { Cation } \\
\text { Charge }\end{array}$} & \multicolumn{4}{|c|}{$\begin{array}{c}\text { \# Coordinating Cations } \\
\left(N_{i}\right)\end{array}$} \\
\hline & & & & & $\mathbf{A l}_{\mathbf{O}}$ & Si & $\mathbf{A l}_{\mathrm{T}}$ & $\mathbf{H}$ \\
\hline Oe1 & Hanging $\equiv$ Si-OH & -0.95000 & 2.00 & 0.95000 & - & 1 & - & 1 \\
\hline $\mathrm{Oe} 2$ & Indented $\equiv \mathrm{Si}-\mathrm{OH}$ & -0.95000 & 2.00 & 0.95000 & - & 1 & - & 1 \\
\hline Oe3 & Octahedral $\equiv \mathrm{Al}_{\mathrm{O}}-\mathrm{OH}_{2}$ & -0.84760 & 2.50 & 1.34760 & 1 & - & - & 2 \\
\hline Oe4 & Hanging $\equiv \mathrm{Al}_{\mathrm{T}}-\mathrm{OH}$ & -1.06875 & 1.75 & 0.81875 & - & - & 1 & 1 \\
\hline Oe 5 & Indented $\equiv \mathrm{Al}_{\mathrm{T}}-\mathrm{OH}$ & -1.06875 & 1.75 & 0.81875 & - & - & 1 & 1 \\
\hline Oe6 & Bridging $\equiv$ Si-O- $-\mathrm{Al}_{\mathrm{O}} \equiv$ & -1.28750 & 1.50 & 0.78750 & 1 & 1 & - & - \\
\hline Oe7 & Bridging $\equiv \mathrm{Al}_{\mathrm{T}}-\mathrm{O}-\mathrm{Al}_{\mathrm{O}} \equiv$ & -1.40625 & 1.25 & 0.65625 & 1 & - & 1 & - \\
\hline $\mathrm{Al}_{\mathrm{O}}$ & Octahedral edge Al & 1.81250 & - & - & - & - & - & - \\
\hline
\end{tabular}




\subsection{Stability of illite edge and basal surfaces}

Preliminary MD simulations showed that the doubly-protonated aluminol site $\equiv \mathrm{Al}_{\mathrm{O}}-\mathrm{OH}_{2}$ is unstable when simulated as described above. In our preliminary simulations, the $-\mathrm{OH}_{2}$ group frequently detached from the clay surface, perhaps because of its very small net charge of $+0.0024 \mathrm{e}[+0.425 \mathrm{e}$ for each $\mathrm{H}$ atom according to CLAYFF, -0.8476 e for the Oe3 atom according to Eq. (1)]. On the CLAYFF model, O atoms are not strictly bonded to the $\mathrm{Al}$ and $\mathrm{Si}$ metal centers, so Coulomb interactions are important to the integrity of the clay structure. Supporting quantum mechanical calculations performed using a small muscovite (110) edge model showed that the detachment of $-\mathrm{OH}_{2}$ groups is not simply an artifact of the MD simulation methodology. These calculations demonstrate that the region mid-way between the $-\mathrm{OH}_{2}$ group and the underlying $\mathrm{Al}$ atom has very little electron density (see Electronic Annex). The $\equiv \mathrm{Al}_{\mathrm{O}}-\mathrm{OH}_{2}$ bond is distinct from other Al-O(H) bonds, with the charge neutral $\mathrm{OH}_{2}$ ligand attracted to the aluminum by van der Waals interaction with the permanent $\mathrm{OH}_{2}$ dipole. These findings are consistent with previous DFT calculations with small pyrophillite clusters showing that the $\mathrm{Al}-\mathrm{OH}_{2}$ bond is readily broken by thermal motion (Martins et al., 2014; Lavikainen et al., 2015). To account for the weakness of the $\equiv \mathrm{Al}_{\mathrm{O}}-\mathrm{OH}_{2}$ bond, we slightly modified the partial charge distribution in the $-\mathrm{OH}_{2}$ group formed by Oe3 atoms to match that of the SPC/E water model. We transferred the small amount of residual charge to the underlying $\mathrm{Al}$ atom.

To illustrate the stability of our edge surface model, a snapshot of the 1:1 Na:Cs simulation after $50 \mathrm{~ns}$ is shown in Fig. 2. All water molecules are hidden except those that were initially part of the octahedral coordination shell of edge $\mathrm{Al}$ atoms. All hydroxyl groups remained bound to the edge surface, while most of the edge water 
molecules (i.e., $-\mathrm{OH}_{2}$ groups) detached from the surface. $\mathrm{A}$ few edge $\mathrm{Al}$ atoms (blue) were observed to "pop" out of the structure without becoming completely dissociated. It is apparent that the edges have remained mostly intact throughout the course of the simulation, and there is no evidence of significant instability. Our simulations yield much more stable edge surfaces than other recent MD simulations (Newton \& Sposito, 2015; Newton et al., 2016), perhaps because the greater negative charge of Oe6 atoms predicted by Eq. (1) helped stabilize $\equiv \mathrm{Si}-\mathrm{O}-\mathrm{Al}_{\mathrm{O}} \equiv$ bridges in our simulations.

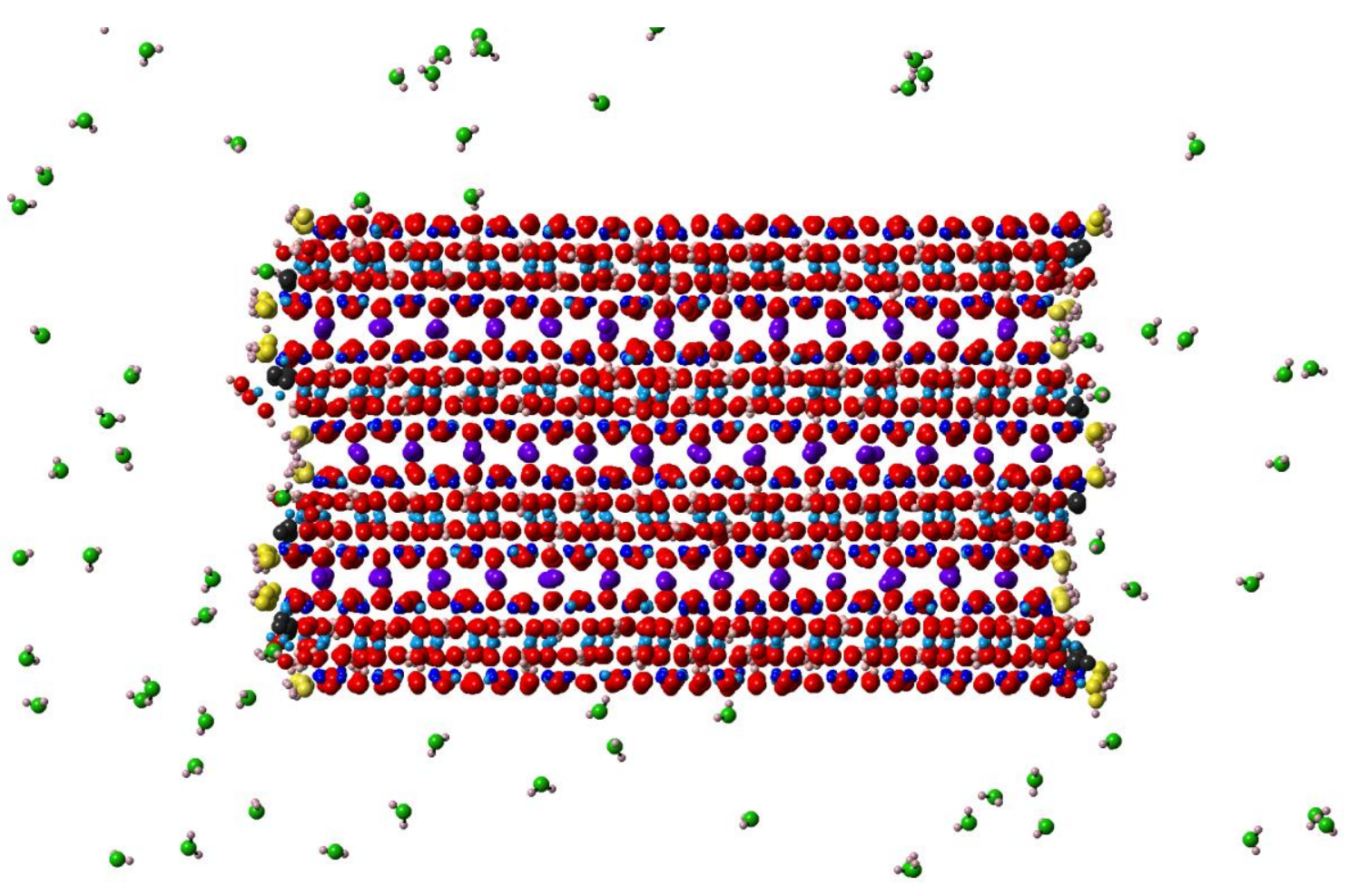

Figure 2. Molecular dynamics simulation snapshot at the end of a $50 \mathrm{~ns}$ production run. Water molecules and $\mathrm{Na}, \mathrm{Cs}$, and $\mathrm{Cl}$ ions are not shown. Edge oxygen atoms are colored for ease of differentiation: $\equiv \mathrm{Al}_{\mathrm{O}}-\mathrm{OH}_{2}$ oxygens $(\mathrm{Oe} 3)$ are in green; $\equiv \mathrm{Si}-\mathrm{OH}$ and $\equiv \mathrm{Al}_{\mathrm{T}}-\mathrm{OH}$ oxygens $(\mathrm{Oe} 1, \mathrm{Oe} 2$, Oe $4, \mathrm{Oe} 5)$ are in yellow; $\equiv \mathrm{Si}-\mathrm{O}-\mathrm{Al}_{\mathrm{O}} \equiv$ and $\equiv \mathrm{Al}_{\mathrm{T}}-\mathrm{O}-\mathrm{Al}_{\mathrm{O}} \equiv$ oxygens (Oe6, Oe7) are in black. Other colors are as in Fig. 1.

Preliminary MD simulations showed that the siloxane surface is unstable if charge-balancing $\mathrm{K}$ ions are randomly distributed in the anhydrous interlayers, as noted 
in section 2.1. Therefore, we used a newly developed methodology based on stochastic sampling techniques to optimally distribute $\mathrm{K}$ ions in the anhydrous interlayers (Pestana et al., in review). Our analysis of 20 optimized illite structures suggests that clustering of $\mathrm{K}$ ions in regions that contain more $\mathrm{Si}$ to $\mathrm{Al}$ isomorphic substitutions is energetically favorable. Ionic sites that have at least three neighboring $\mathrm{Si}$ atoms substituted by $\mathrm{Al}$ are all occupied by $\mathrm{K}$ ions.

\subsection{Molecular dynamics simulations}

Standard (unconstrained) MD simulations were carried out to assess the stability of the illite structure and to evaluate the thermodynamics and kinetics of Na-Cs exchange on different surface sites. Briefly, MD simulation trajectories were calculated over intervals in excess of $50 \mathrm{~ns}$ for ten different initial aqueous solution compositions at fixed total numbers of electrolyte ions and various mole fraction of $\mathrm{Cs}^{+}\left(x_{\mathrm{Cs}}=N_{\mathrm{Cs}} /\left(N_{\mathrm{Na}}+N_{\mathrm{Cs}}\right)=\right.$ $0.1,0.2,0.3,0.4,0.5,0.6,0.7,0.8,0.9$ and 1.0$)$. The total electrolyte concentration translates to an average ionic strength $I=0.70 \pm 0.01 \mathrm{M}$, equivalent to that of seawater.

All systems were initially equilibrated for $100 \mathrm{ps}$ in the NVE ensemble (fixed number of atoms, volume, and total energy), then for $2 \mathrm{~ns}$ in the NPT ensemble (fixed number of atoms, pressure, and temperature). Production runs were performed in the NPT ensemble at $P=0 \mathrm{MPa}$ and $T=298 \mathrm{~K}$. Temperature and pressure were constrained using the Nose-Hoover thermostat and barostat. Newton's equations of motion were solved using the Verlet algorithm with a 1 fs time step. The dynamics of ions and clay atoms were simulated with no constraints (the clay particle was fully flexible). Water molecules were kept rigid using the SHAKE algorithm (Ryckaert et al., 1977). 
Electrostatic and dispersion interactions beyond a cutoff of $15.0 \AA$ were computed by Ewald summation with the particle-particle/particle-mesh (PPPM) method.

\subsection{Thermodynamic integration simulations}

Based on our MD simulation methodology, thermodynamic integration (TI) calculations were carried out to predict the Gibbs free energies of ion exchange reactions between $\mathrm{Na}, \mathrm{K}$, and $\mathrm{Cs}$ in bulk liquid water, on illite external basal surfaces, and in anhydrous interlayers. The TI method is routinely used to predict free energies of solvation and the cation binding selectivity of proteins (Straatsma et al., 1986; Åqvist, 1990; Frenkel and Smit, 2002). Only two MD simulation studies have applied the TI method to predict free energies of cation exchange on clay minerals (Teppen and Miller, 2006; Rotenberg et al., 2009). Both studies focused on the interlayer nanopores of swelling clay minerals. More recently, Okumura et al. (2013) used the TI method with DFT simulations of illite frayed edges and predicted that replacement of $\mathrm{K}$ by $\mathrm{Cs}$ at wedge sites is unfavorable unless the illite basal spacing increases by about $1 \AA$.

Briefly, our TI calculations consisted in simulating a K-exchanged illite nanoparticle in the NPT ensemble $(P=0 \mathrm{MPa}, T=298 \mathrm{~K})$ using the MD simulation methodology described above. Then, selected $\mathrm{K}$ ions on the illite surface were progressively transformed to $\mathrm{Na}$ or $\mathrm{Cs}$ by modifying their short-range interaction potentials (more precisely, their size and well-depth parameters in the Lennard-Jones 612 interaction model) in a series of small steps. Each TI simulation consisted of 15 ( $\mathrm{K}$ to $\mathrm{Cs}$ ) or 25 (K to $\mathrm{Na}$ ) small transformations. Each adjustment to the LJ interaction parameters of the cations of interest was sufficiently small that the total energy of the 
system changed by less than $2.5 \mathrm{~kJ} \mathrm{~mol}^{-1}$ (Straatsma et al., 1986; Teppen and Miller, 2006). Each small transformation step was followed by $2.5 \mathrm{~ns}$ of equilibration and $1.5 \mathrm{~ns}$ of simulation in the NPT ensemble. The absence of hysteresis was verified by carrying out all TI simulations in both directions. Additional calculation details are provided in the Electronic Annex.

In order to examine the cation-exchange selectivity of different surface sites, we carried out four different TI simulations. The first consisted in transforming all cations on the external basal surface of our model illite nanoparticle. The second consisted in transforming all cations in the anhydrous interlayers. The third consisted in transforming a small subset of the interlayer cations in our simulated particle (more precisely, 10 out of 277 interlayer cations). The fourth consisted in transforming a single cation in a simulation cell containing one cation and 999 water molecules.

\section{RESUltS AND DisCUSSION}

\subsection{Adsorption sites on illite basal and edge surfaces}

As described above, we carried out ten MD simulations of $\mathrm{NaCl}-\mathrm{CsCl}$ mixed electrolytes with a range of $\mathrm{Na}$ : $\mathrm{Cs}$ ratios to examine the competitive adsorption of $\mathrm{Na}$ and Cs on illite edge and basal surfaces. Time integrated $\mathrm{Na}, \mathrm{Cs}$, and water $\mathrm{O}$ density maps were used to identify ion adsorption sites on illite edge and basal surfaces for each of the 10 simulations. A representative density map for Cs is shown in Fig. 3 for the simulation with a 1:1 Na:Cs ratio. Cesium adsorption occurs preferentially at discrete sites on the basal and edge surfaces. On the basal surfaces, the Cs density maxima are consistent with cesium adsorbing primarily as an inner-sphere surface complex (ISSC) on the ditrigonal 
cavities of the siloxane surface, as shown in previous studies of Cs adsorption on mica (Sakuma and Kawamura, 2011; Lee et al., 2012) and smectite (Marry et al., 2008).

On the edge surface, Cs adsorbs in the plane of the anhydrous interlayers at a distance that matches the periodicity of the distribution of interlayer $\mathrm{K}$ ions. Interlayer $\mathrm{K}$ ions are located in pockets formed by two ditrigonal cavities on opposite siloxane surfaces. Our results indicate that edge Cs ions adsorb primarily at sites where cleaved pockets are exposed at the edge surface. Our results further show that Cs ions have a much greater affinity for edge $\mathrm{H}$-sites than for edge I-sites, in agreement with the distribution of atomic partial charges in our model of edge $\mathrm{O}$ atoms (edge Oe6 and Oe7 atoms, which are closer to the $\mathrm{H}$-site, have more negative charge than edge Oe 3 atoms, which are closer to the I-site). Because of the symmetry of the illite structure, positive and negative charge excess sites form neighboring pairs that give the $\mathrm{H}$ - and I- sites their distinct adsorption behavior.

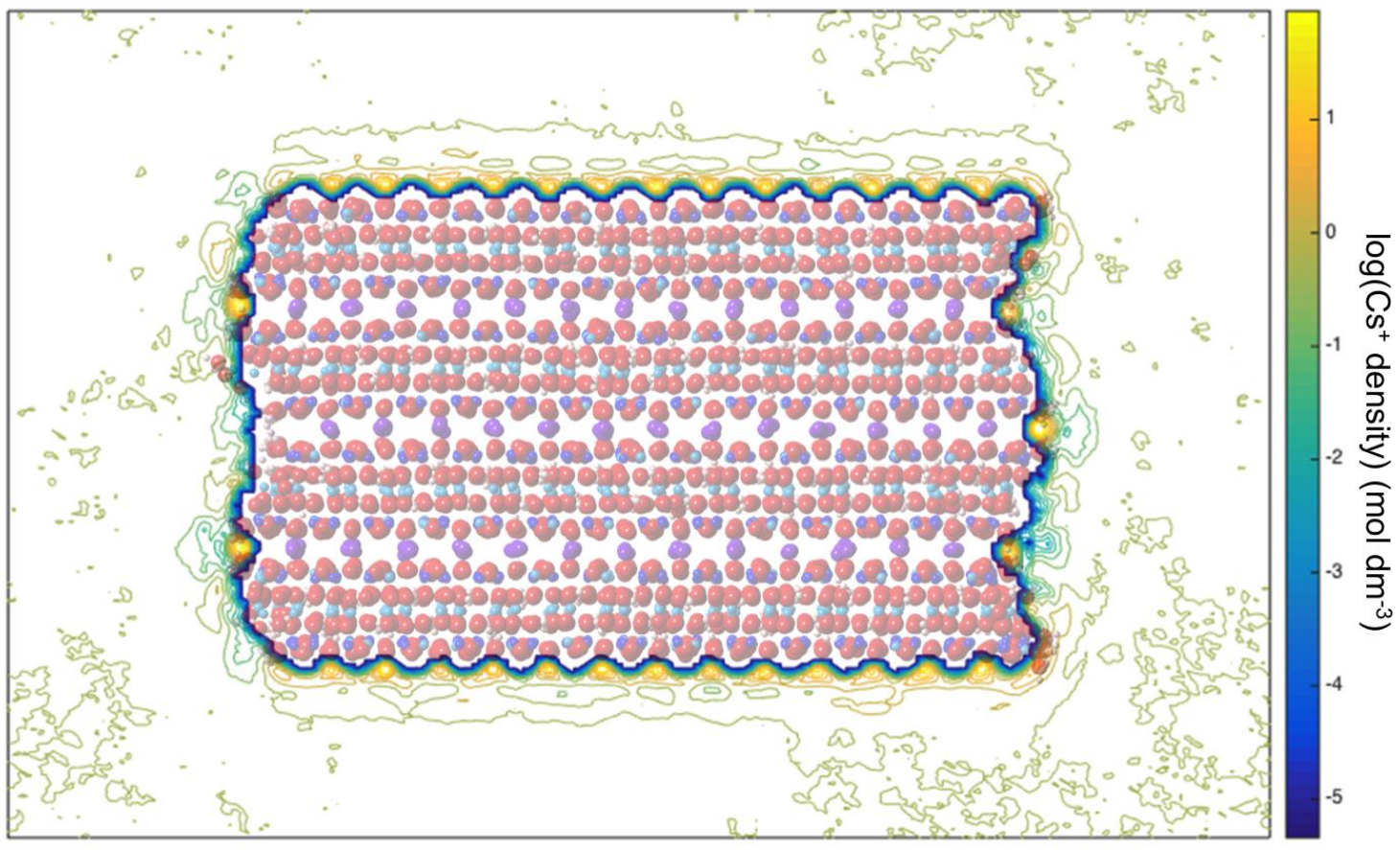


Figure 3. Map of Cs density averaged over the entire $50 \mathrm{~ns}$ simulation with $x_{\mathrm{Cs}}=0.5$. Cesium primarily binds to ditrigonal cavities on the basal surfaces and to "cleaved cavities" at edge surface H-sites.

One-dimensional atomic density profiles yield further insight into the adsorption mechanisms of $\mathrm{Na}$ and $\mathrm{Cs}$ on the basal and edge surfaces. Density profiles of $\mathrm{Na}$ and $\mathrm{Cs}$ on the basal surfaces are given in Fig. 4a-b for low $\left(x_{\mathrm{Cs}}=0.1\right)$ and high $\left(x_{\mathrm{Cs}}=0.9\right) \mathrm{Cs}$ end-member simulations. Density profiles adjacent to the basal surfaces are broadly consistent with the triple layer model (TLM) of the electrical double layer (EDL), whereby adsorbed ions form inner- or outer-sphere surface complexes (ISSC, OSSC) or take part in the diffuse ion swarm, i.e., adsorbed ions form distinct species separated from the surface by zero, one, or more than one layers of water molecules (Hayes and Leckie, 1987; Hiemstra and Van Riemsdijk, 1996; Bourg and Sposito, 2011). Cesium adsorbs almost exclusively as a single type of ISSC, as observed experimentally on the basal surface of mica (Lee et al., 2012). Sodium has a more complex behavior: based on the relative location of $\mathrm{Na}$ and water density peaks in Fig. 4, Na forms two types of ISSC as well as an OSSC. Our finding that Na forms primarily ISSC on illite supports the emerging view that electrolyte ions can adsorb significantly as ISSC, in contradiction with the prevailing assumption in surface complexation models based on the triple layer model that restricts these species to OSSC and the diffuse swarm. The $\mathrm{Cl}$ density profile shows a significant density peak in Fig. 4a, suggesting that $\mathrm{CsCl}$ ion pairs have a significant affinity for illite basal surfaces. 

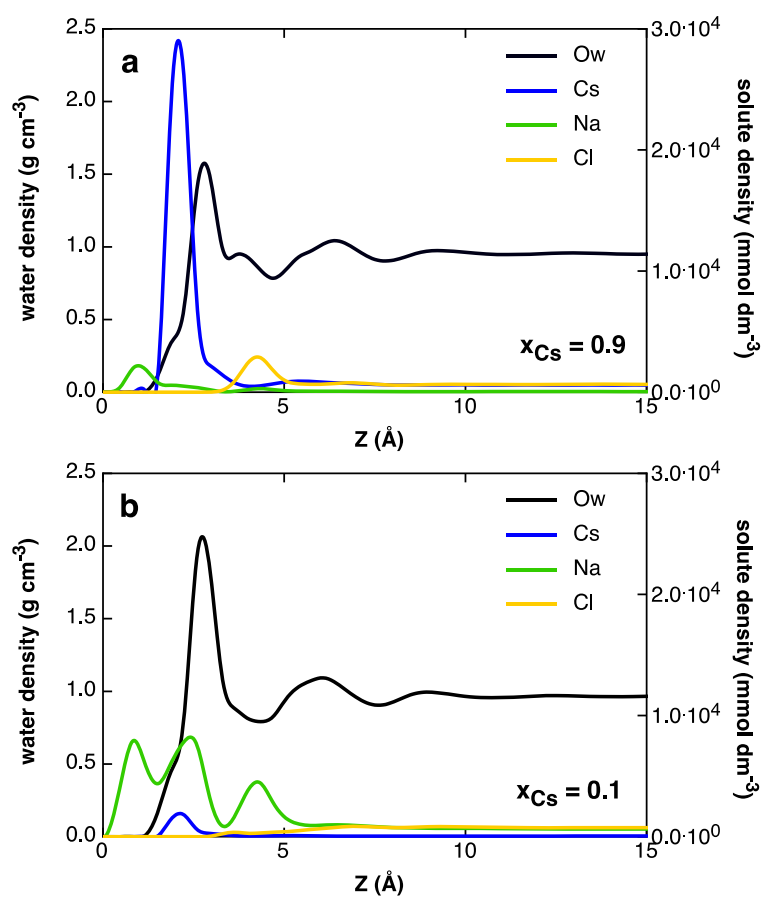

Figure 4. Density profiles of solutes $(\mathrm{Na}, \mathrm{Cs}$, and $\mathrm{Cl})$ and water oxygen atoms $(\mathrm{Ow})$ adjacent to illite basal surfaces during our $50 \mathrm{~ns}$ simulations at $x_{\mathrm{Cs}}=0.9$ (a) and $x_{\mathrm{Cs}}=0.1$ (b). Distances $(z)$ are reported relative to the distance where all solute and solvent ion concentrations go to zero.

To a first approximation, the location of ISSC should be determined primarily by the size of the adsorbed ion (Predota et al., 2004; Ridley et al., 2009; Lee et al., 2010). For consistency with previous studies, we define the location of adsorbed ions on the illite basal surface as the distance $z^{*}$ from the position of the plane of surface $\mathrm{O}$ atoms. The density peak of Na ISSC $\left(z^{*}=1.25 \AA\right)$ is much closer to that surface than expected based on the sum of the hard-sphere radii of $\mathrm{O}$ and $\mathrm{Na}$ atoms $\left(r_{\mathrm{O}} \approx 1.6\right.$ and $r_{\mathrm{Na}} \approx 1.3 \AA$ according to the interatomic potential parameters used in the present study). This large difference indicates that $\mathrm{Na}$ ions are deeply ensconced in the ditrigonal cavities of the siloxane surface. The Cs density peak is located further from the plane of basal surface $\mathrm{O}$ atoms $\left(z^{*}=2.26 \AA\right)$ in agreement with its larger hard-sphere radius $\left(r_{\mathrm{Cs}} \approx 1.9 \AA\right)$. $\mathrm{A}$ 
smaller fraction of the hard-sphere radius of Cs sits below the basal surface indicating that $\mathrm{Cs}$ ions do not fit as snugly in the ditrigonal cavities as does $\mathrm{Na}$.

The location of the Cs density peak in Fig. 4 is remarkably consistent with the peak position measured by X-ray reflectivity for Cs ions adsorbed at the mica-water interface, $z^{*}=2.26 \pm 0.01 \AA$ (Lee et al., 2012). In the case of Na, experimental measurements of the location of adsorbed ISSC do not exist. However, the two ISSC peaks are located much closer to the surface than in previous MD simulations carried out with a rigid clay structure. For example, Bourg and Sposito (2011b) observed Na ISSC at $z^{*}=2.6 \AA$ in MD simulations of Na-smectite carried out with the same set of interatomic potential parameters. The difference is likely due to the isomorphic substitutions being located in the tetrahedral sheet (closer to the basal surface than in studies of smectite clay minerals) and, also, to the simulations presented here being performed using a flexible clay structure. The CLAYFF model, when used to model flexible phyllosilicate sheets, is known to predict an unphysical relaxation of the siloxane surface that transforms the ditrigonal cavities to larger hexagonal cavities (Zaunbrecher et al., 2015). The deep entry of $\mathrm{Na}$ in the hexagonal cavities is an artifact of this unphysical relaxation.

On the edge surfaces, we calculated atomic density profiles as a function of distance from the surface in two equally sized regions centered on the $\mathrm{H}$ and I edge sites. Because of the corrugated topography of the edge surface, the choice of reference plane where $z=0$ is somewhat arbitrary. In Fig. 5, this plane was chosen as the location of closest approach of water $\mathrm{O}$ atoms. With this choice of reference plane, ions located at $z$ values smaller than about $3 \AA$ form ISSC, while ions located at $z$ values of about 3 to $6 \AA$ form OSSC. Ion density profiles shown in Fig. 5 confirm that Cs ions adsorb primarily as 
ISSC on both H- and I-sites. Sodium ions adsorb only on the H-sites and they have a small preference for forming OSSC rather than ISSC. In each cation density profile, the low density between ISSC and OSSC suggests the presence of an energy barrier to edge ion exchange.
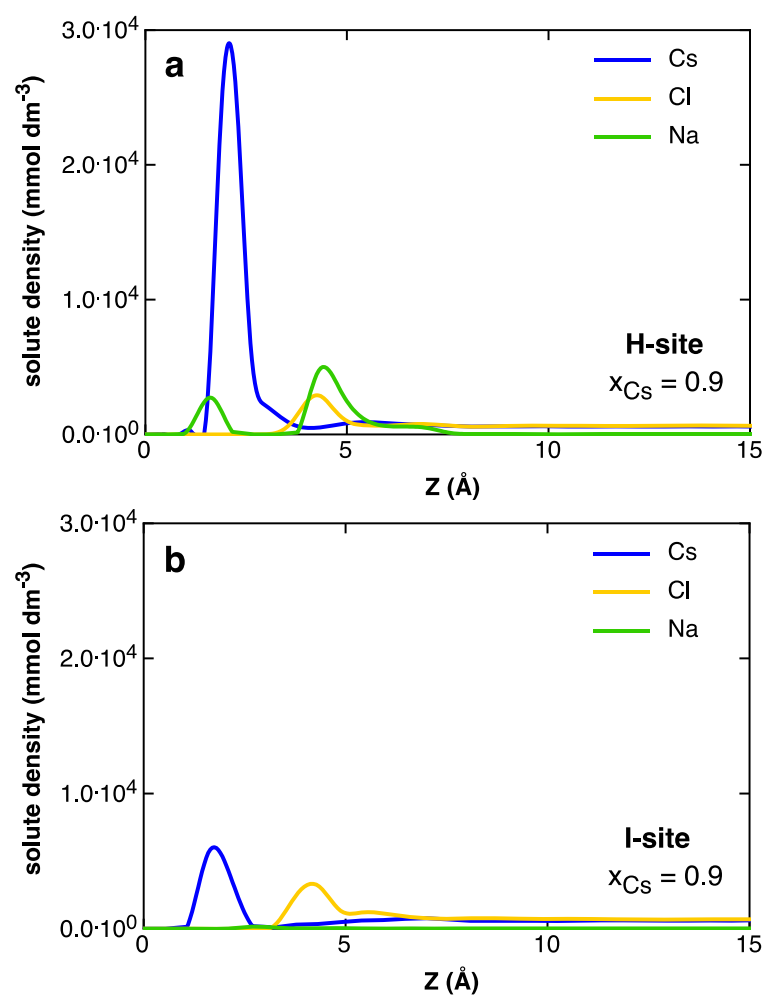

Figure 5. Density profiles of adsorbed ions adjacent to hanging (a) and indented (b) sites on the illite edge surface.

\subsection{Cs adsorption selectivity on basal and edge surfaces predicted by MD simulation}

Cation adsorption on different illite surface sites was quantified as a surface excess $\left(n_{i}{ }^{\mathrm{w}}, \mathrm{mol} \mathrm{m}{ }^{-2}\right)$ using the well established formulation (Sposito, 2004):

$n_{i}^{w}=\frac{1}{A} N_{i} \quad c_{i} V^{f l}$

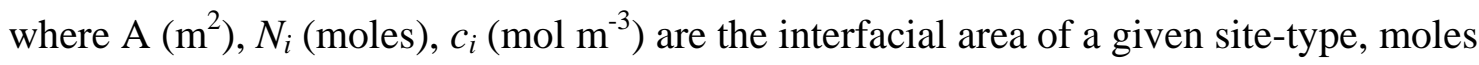
of $i$ in volume $V^{f l}\left(\mathrm{~m}^{3}\right)$ adjacent to the site, and bulk aqueous concentration of $i$ far from 
the surface. Equation 2 allows a direct comparison of the average density of adsorbed cations on each site (irrespective of adsorption mechanism) in units of moles per $\mathrm{m}^{2}$. Macroscopic measurements of adsorption are often reported as a specific surface excess over the entire solid phase, referred to here as $\left(n_{i}{ }^{\mathrm{W}}\right)_{\text {macro }}$ in $\mathrm{mol} \mathrm{kg} \mathrm{kg}^{-1}$ (Sposito, 2004). If the specific surface area contributed by different types of surfaces $\left(a_{\mathrm{s}, \text { basal }}, a_{\mathrm{s}, \mathrm{H} \text {-edge }}\right.$, and $a_{\mathrm{s}, \mathrm{I} \text {-edge }}$ in $\left.\mathrm{m}^{2} \mathrm{~kg}^{-1}\right)$ is known, the value of $\left(n_{i}{ }^{\mathrm{w}}\right)_{\text {macro }}$ can be predicted from the molecular-scale values of $n_{i}{ }^{\mathrm{w}}$ on each type of surface (in mol m${ }^{-2}$ ):

$\left(n_{i}^{w}\right)_{\text {macro }}=\left(a_{s} n_{i}^{w}\right)_{\text {basal }}+\left(a_{s} n_{i}^{w}\right)_{H \text { edge }}+\left(a_{s} n_{i}^{w}\right)_{I \text { edge }} \cdot$

In the simulations performed here, $a_{\mathrm{s}, \text { basal }}=1.76 \times 10^{5} \mathrm{~m}^{2} / \mathrm{kg}$ and $a_{\mathrm{s}, \mathrm{H} \text {-edge }}=a_{\mathrm{s}, \mathrm{I} \text {-edge }}=5.56$ $\times 10^{4} \mathrm{~m}^{2} / \mathrm{kg}$, where edge $H$ - and $I$-site surfaces are defined such that their respective areas are equal to half of the total edge area. Surface, edge-site specific, and total particle values for $\mathrm{Na}$ and $\mathrm{Cs}$ surface excess are summarized in Table EA2 (Electronic Annex) for each of the $10 \mathrm{MD}$ simulations performed. The data are plotted as adsorption isotherms for basal and edge surfaces in Fig. 6.
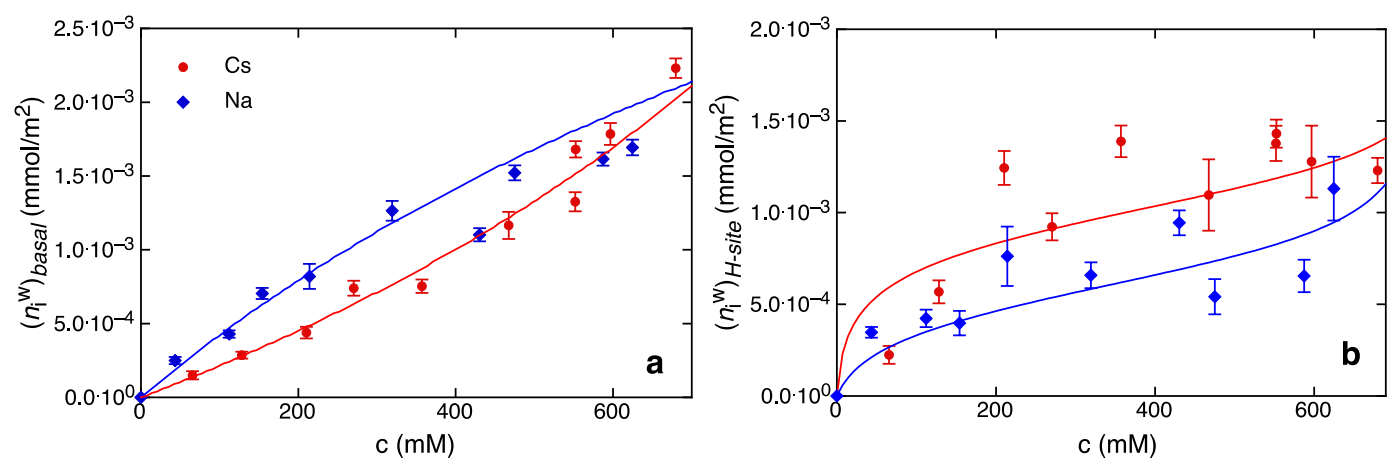

Figure 6. Surface excess adsorption isotherms for $\mathrm{Na}$ (blue diamonds) and $\mathrm{Cs}$ (red circles) determined from the ten $50 \mathrm{~ns}$ MD simulation runs on (a) basal surfaces normalized to basal surface area and (b) edge $\mathrm{H}$-sites normalized to $\mathrm{H}$-edge area. Isotherms were fitted using the thermodynamic model given by Eqs. 8-9. 
Geochemical modeling. We used a single geochemical model to describe the adsorption results shown in Table EA3, Fig. 6, and Fig. 7. In this model, Cs adsorption on a cation exchange site of Na-illite is described with the equation:

$$
X \mathrm{Na}^{+}(s)+\mathrm{Cs}^{+}(a q) \leftrightarrow X C s^{+}(s)+N a^{+}(a q),
$$

with the corresponding mass action equation (Bourg \& Sposito, 2011a),

$$
K_{e q}^{N a / C s}=\frac{a_{N a} a_{X C S}}{a_{C s} a_{X N a}} .
$$

Here, we assume that the activity coefficients of surface sites are proportional to their mole fraction on the surface $(x)$ times an activity coefficient $(\gamma)$. This yields:

$$
a_{X i}={ }_{X i} x_{i}
$$

We use the regular solution model to describe surface solution behavior,

$$
{ }_{X i}=\exp \left(x_{X j}^{2}\right)
$$

where for a mixture of adsorbed ions $i$ and $j, x_{X i}$ is the fraction of $\mathrm{X}$ sites occupied by adsorbed ion $i\left(x_{X_{i}}=n_{i} /\left(n_{\mathrm{i}}+n_{j}\right)\right)$, and $\alpha$ is a free parameter that captures the excess free energy of mixing of surface $\mathrm{Na}$ and $\mathrm{Cs}$. This model can be used to describe the thermodynamics of binary solid solutions (Kulik et al., 2012) and assumes that the excess free energy of mixing is entirely due to enthalpic effects. If $\alpha=0$, the regular solution model simplifies to the ideal surface solution model. Equations 4-6, when combined with a mass balance on surface sites (i.e., $n_{t o t}=n_{i}+n_{j}$ ), yield the following expressions for the specific surface excesses of $\mathrm{Na}$ and Cs:

$$
n_{N a}=\frac{n_{t o t}}{1+K_{e q}^{N a / C s} \frac{a_{C s} X N a}{a_{N a X C s}}}
$$




$$
n_{C s}=\frac{n_{t o t}}{1+\frac{1}{K_{e q}^{N a / C s}} \frac{a_{N a X C s}}{a_{C s \quad X N a}}}
$$

If the activity coefficients of adsorbed species are unknown, Eq. 5 can be replaced with an empirical model such as the Vanselow selectivity model (Vanselow, 1932):

$$
K_{V}^{N a / C s}=\frac{a_{N a} x_{X C s}}{a_{C S} x_{X N a}}
$$

where the Vanselow selectivity coefficient, $K_{\mathrm{V}}$, may vary with experimental conditions unless surface solution behavior is ideal. For ideal surface solutions, the ratio of surface activities is equivalent to the ratio of surface excess concentrations and $K_{\mathrm{V}}$ becomes equal to the thermodynamic equilibrium constant $K_{\mathrm{eq}}$. Finally, if the activity coefficients of dissolved species are unknown, a conditional selectivity coefficient $\left(K_{\mathrm{c}}\right)$ can be defined that is expressed in terms of measurable quantities including aqueous and surface species concentrations,

$$
K_{c}^{N a / C s}=\frac{c_{N a} x_{X C s}}{c_{C s} x_{X N a}} .
$$

This equation follows immediately from Eq. 10 if the Davies equation is used to model activity coefficients of aqueous species. For ideal surface solutions, Eqs. 5 and 10-11 yield the relation: $K_{\mathrm{eq}}^{\mathrm{Na} / \mathrm{Cs}}=K_{\mathrm{v}}^{\mathrm{Na} / \mathrm{Cs}}=K_{\mathrm{c}}^{\mathrm{Na} / \mathrm{Cs}}\left(\gamma_{\mathrm{Na}} / \gamma_{\mathrm{Cs}}\right)$.

Sorption on basal and edge surface sites. Adsorption isotherms calculated with Eqs. 8-9 are plotted in Fig. 6 for basal and edge surfaces. For simplicity, we assumed that aqueous $\mathrm{Na}$ and Cs have identical activity coefficients. Model curves were fitted using unconstrained nonlinear optimization of two parameters: $K_{\mathrm{eq}}{ }^{\mathrm{Na} / \mathrm{Cs}}$, and $\alpha$. The total site 
capacities of basal and edge $\mathrm{H}$-site surfaces $\left(n_{\mathrm{tot}}=2.17 \pm 0.02 \mu \mathrm{mol} \mathrm{m} \mathrm{m}^{-2}\right.$ and $1.66 \pm 0.18$ $\mu \mathrm{mol} \mathrm{m} \mathrm{m}^{-2} 2$ s.e., respectively) were determined based on the average combined surface occupancy by $\mathrm{Na}$ and $\mathrm{Cs}$ in all MD simulations.

In the case of illite basal surfaces (Fig. 6a), adsorption of $\mathrm{Na}$ and $\mathrm{Cs}$ is approximately linear in the simulated concentration range, in other words, adsorption is consistent with a linear partitioning coefficient $K_{\mathrm{d}}=n_{i} / C_{i}$, where $C_{i}$ is the aqueous concentration of ion $i$. The optimized surface solution activity parameter $\alpha$ was very close to $0(\alpha=0.01$ and $-1.2<\alpha<0.3,2$ s.e $)$, indicating that ion exchange on the basal surfaces follows ideal solution behavior. This near-ideality indicates that $\mathrm{Na}-\mathrm{Cs}$ exchange on illite basal surfaces is not significantly influenced by lateral interactions between adsorbed cations, in agreement with a previous MD simulation study of $\mathrm{Na}-\mathrm{Cs}$ exchange in smectite interlayers (Rotenberg et al., 2009). The best fit was obtained with $K_{\mathrm{eq}}{ }^{\mathrm{Na} / \mathrm{Cs}}=0.7$ $\left(0.6<K_{\mathrm{eq}}^{\mathrm{Na} / \mathrm{Cs}}<0.8,2\right.$ s.e. $)$, indicating that the basal surface is essentially non-selective or slightly selective towards $\mathrm{Na}$. This behavior contrasts with the experimentally observed selectivity of illite basal surfaces towards Cs over Na (Table 1). A plausible explanation is that the unphysical relaxation of ditrigonal cavities on the basal surface in our model illite nanoparticle (noted in section 3.1) results in our model overestimating the affinity of $\mathrm{Na}$ for the illite basal surface.

Ion adsorption on edge $\mathrm{H}$-sites is distinctly different from that observed on the basal surfaces (Fig. 6b). Calculated errors on surface excess values are larger than those associated with the basal adsorption isotherms, because the smaller number of exchange sites and slower exchange kinetics on the edge surfaces (described below) result in poorer statistics. For edge H-sites, the optimized $\alpha=-2.2$ is significantly different from zero (- 
$5.8<\alpha<-0.8,2$ s.e.) indicating that edges are characterized by non-ideal surface solution behavior. The optimized exchange equilibrium constant, $K_{\mathrm{eq}}{ }^{\mathrm{Na} / \mathrm{Cs}}=2.8\left(1.6<K_{\mathrm{eq}}{ }^{\mathrm{Na} / \mathrm{Cs}}<\right.$ 5.0, 2 s.e.), is larger than its basal sorption counterpart. The non-ideal adsorption behavior characteristic of the edge sites indicates that their selectivity behavior depends upon the aqueous solution composition (in particular, on the mole fraction of Cs in the aqueous phase).

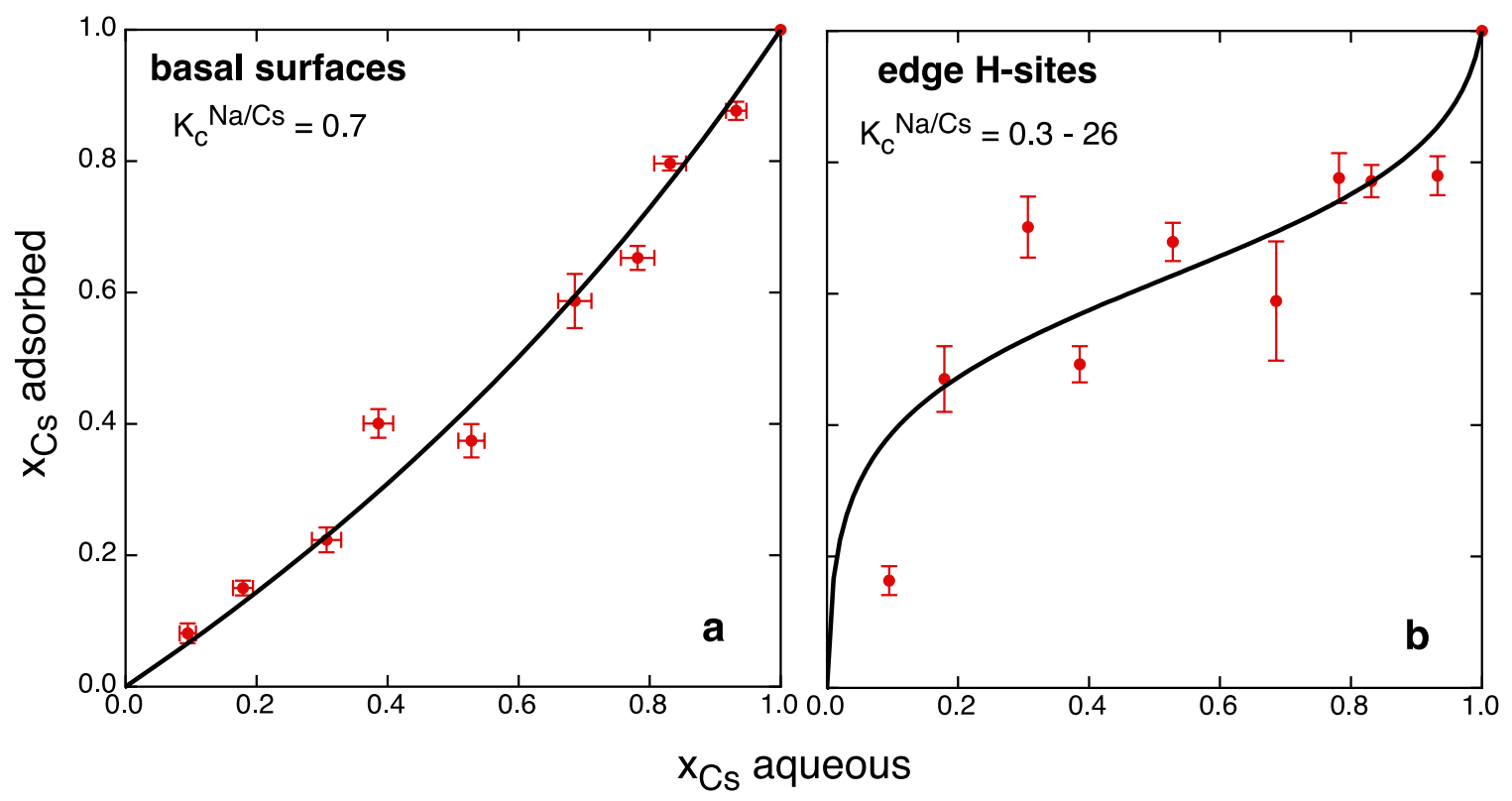

Figure 7. Na-Cs exchange isotherms for (a) basal and (b) edge sites. Basal exchange behavior is consistent with an ideal surface solution, while edges exhibit non-ideal exchange behavior. Edges are significantly Cs-selective at low Cs surface loadings but become increasingly Na-selective as the aqueous mole fraction of Cs approaches 1.0.

Ion exchange on basal and edge surface sites. Exchange selectivity behavior can be illustrated by plotting the aqueous vs. solid mole fractions of Cs (Fig. 7). In this framework, an ideal non-selective isotherm will follow the 1:1 line, a Na-selective isotherm falls below the 1:1 line, and a Cs-selective isotherm falls above the 1:1 line. The conditional selectivity of basal surfaces is modeled in Fig. 7a based on Eq. 11 with a $K_{\mathrm{c}}^{\mathrm{Na} / \mathrm{Cs}}=0.73=K_{\mathrm{eq}}{ }^{\mathrm{Na} / \mathrm{Cs}}$. The results indicate that the simulated illite basal surface is 
slightly Na-selective. The value of $K_{\mathrm{c}}^{\mathrm{Na} / \mathrm{Cs}}$ on basal surfaces is invariant with $x_{\mathrm{Cs}}$ and equal to the calculated equilibrium constant for Eq. 5, in agreement with the ideal surface solution model. The exchange isotherm for the edge H-sites is plotted in Fig. 7b along with the conditional selectivity model (Eq. 11), where adsorption to the edges for $\mathrm{Na}$ and Cs is described by their respective adsorption isotherms (Eqs. 8-9). The adsorption selectivity of I-sites was not calculated, because values of $\mathrm{Cs}$ and $\mathrm{Na}$ surface excess at these sites were typically within error of zero. In stark contrast to the adsorption behavior observed on basal surfaces, Na-Cs exchange at edge $\mathrm{H}$-sites is non-ideal, resulting in a $K_{\mathrm{c}}^{\mathrm{Na} / \mathrm{Cs}}$ value that varies with $x_{\mathrm{Cs}}$. Based on the fitted selectivity model, edge H-sites are Cs-selective $\left(K_{\mathrm{c}}^{\mathrm{Na} / \mathrm{Cs}}=26\right)$ in low-Cs solutions $\left(c_{\mathrm{Cs}}<1 \mathrm{mM}\right)$ and Na-selective $\left(K_{\mathrm{c}}^{\mathrm{Na} / \mathrm{Cs}}=\right.$ $0.31)$ in high-Cs solutions $\left(c_{\mathrm{Cs}}=0.7 \mathrm{M}\right)$.

Cation exchange reactions involving Cs adsorption on illite and smectite are known to be non-ideal, but this non-ideality has been attributed in the past to variations in water activity with changes in salinity and interlayer spacing (Liu et al., 2004; Rotenberg et al., 2009; Bourg \& Sposito, 2011a). In our simulations, insight into the non-ideality of edge ion exchange can be gained by scrutinizing Cs adsorption behavior at H-sites. Ions located in the density maximum location in Fig. 5a are bound to the H-sites as ISSC. With increasing aqueous mole fraction of Cs, the capacity of these sites for monovalent cations $(\mathrm{Na}+\mathrm{Cs})$ actually increases from approximately 0.5 ions per site at $x_{C s}=0.1$ to approximately 0.7 ions per site at $x_{C s}=1.0$. The significant increase in H-site occupancy by inner-sphere complexed ions suggests that Cs changes the structure of the site itself, causing the observed non-ideal adsorption behavior. 


\subsection{Cs adsorption selectivity in anhydrous interlayers predicted by TI simulation}

As noted above, Cs entry in anhydrous illite interlayers was not observed during our ten $50 \mathrm{~ns}$ MD simulation, in agreement with the very slow kinetics of Cs adsorption on the illite slow site (Comans et al., 1991; Comans \& Hockley, 1992). To complement our unconstrained MD simulation results, we used the thermodynamic integration (TI) technique to predict the Gibbs free energy change associated with alchemical transformations of $\mathrm{Na}$ to $\mathrm{Cs}$ in bulk liquid water, on external basal surfaces, and in anhydrous interlayers. More precisely, our calculations yielded the free energy change $\Delta G^{\mathrm{Na} / i}$ associated with the replacement of Na by $i$, where $i=\mathrm{K}$ or Cs. The difference between our predicted values of $\Delta G^{\mathrm{Na} / i}$ on the surface $\left(\Delta G_{\mathrm{ads}}^{\mathrm{Na} / i}\right)$ and in solution $\left(\Delta G_{\mathrm{aq}}^{\mathrm{Na} / i}\right)$ yields the Gibbs free energy of the cation exchange reaction between $\mathrm{Na}$ and $i\left(\Delta G_{\mathrm{ex}}{ }^{\mathrm{N} /} / \mathrm{i}\right)$ : $\Delta G_{\mathrm{ex}}^{\mathrm{Na} / i}=\Delta G_{\mathrm{ads}}{ }^{\mathrm{N} a / i}-\Delta G_{\mathrm{aq}}^{\mathrm{Na} / i}$.

From our predicted values of $\Delta G_{\mathrm{ex}}{ }^{\mathrm{Na} / i}$, we calculated the ion-exchange selectivity coefficient between $\mathrm{Na}$ and $i$ with the relation:

$K_{\mathrm{eq}}{ }^{\mathrm{Na} / i}=\exp \left(-\Delta G_{\mathrm{ex}}{ }^{\mathrm{Na} / i} / R T\right)$,

where $R$ is the ideal gas constant and $T=298 \mathrm{~K}$. Our predicted values of $\Delta G_{\text {aq }}{ }^{\mathrm{Na} / \mathrm{K}}=73 \pm$ $1 \mathrm{~kJ} \mathrm{~mol}^{-1}, \Delta G_{\mathrm{aq}}^{\mathrm{Na} / \mathrm{K}}=89 \pm 1 \mathrm{~kJ} \mathrm{~mol}^{-1}$, and $\Delta G_{\mathrm{aq}}{ }^{\mathrm{Na} / \mathrm{Cs}}=113 \pm 1 \mathrm{~kJ} \mathrm{~mol}^{-1}$ are almost equal to the experimental values of 70, 90, and $115 \mathrm{~kJ} \mathrm{~mol}^{-1}$, respectively (Marcus, 1991). Our predicted values of the free energy of exchange are reported in Fig. 8 as a function of $\Delta G_{\mathrm{aq}}{ }^{\mathrm{Na} / i}$ (the free energy of hydration relative to the value for sodium). The values for $\mathrm{Na}$, $\mathrm{K}$, and Cs are highlighted with larger symbols. Values of $\log K_{\text {eq }}$ calculated from the results presented in Fig. 8 are shown in Table 3. 


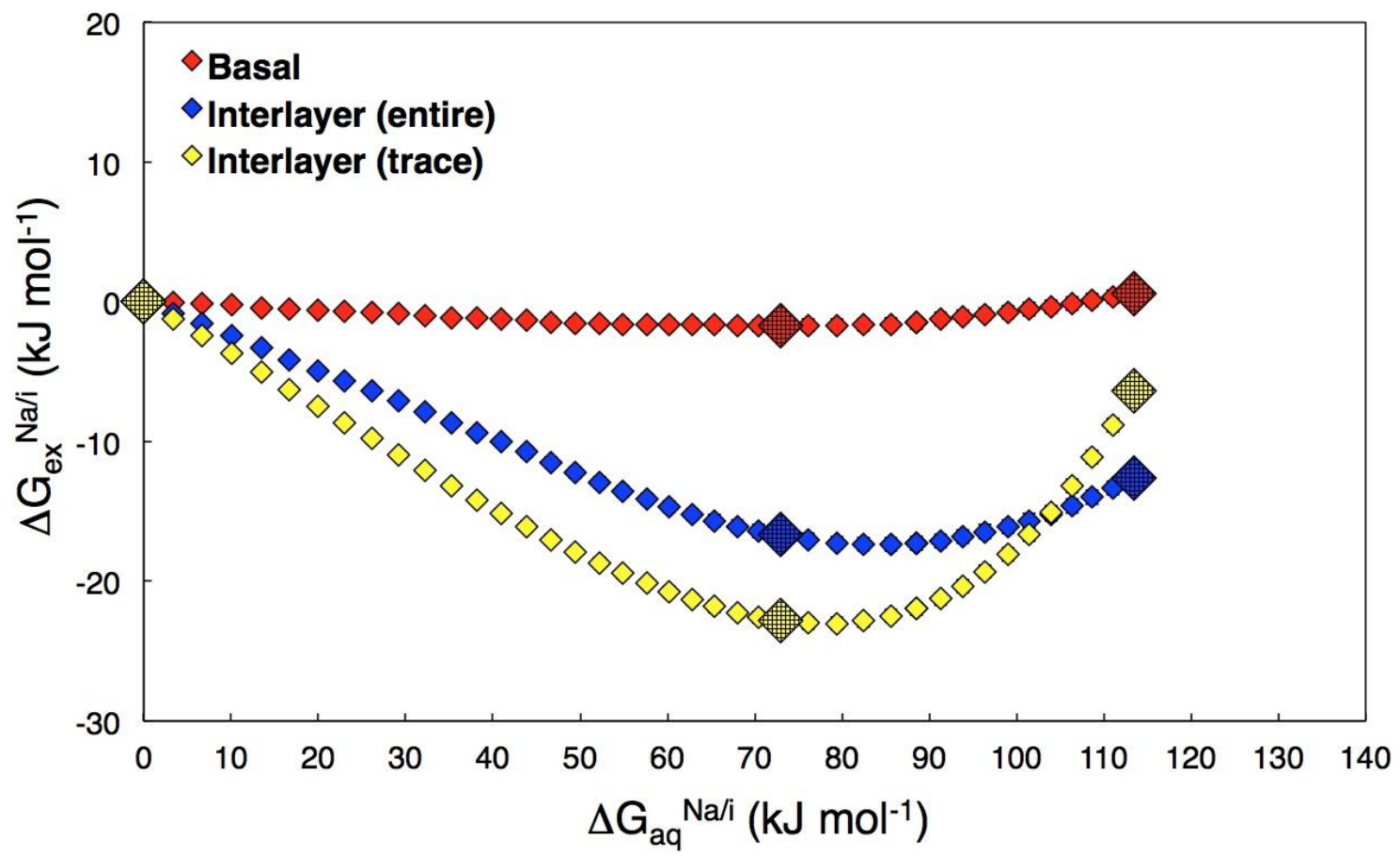

Figure 8. Thermodynamic integration (TI) prediction of the Gibbs free energy of cation exchange (relative to $\mathrm{Na}$ ) as a function of the Gibbs free energy of hydration (relative to $\mathrm{Na}$ ). The different colors show results obtained at three different sites on the illite surface: on the external basal surface (red), in collapsed interlayers where all interlayer ions are simultaneously transformed (blue), and in collapsed interlayers where most ions remain $\mathrm{K}^{+}$while a few dispersed ions are transformed (yellow). Large symbols show free energies obtained for $\mathrm{Na}, \mathrm{K}$, and $\mathrm{Cs}$ (from left to right); smaller symbols show the intermediate steps of the alchemical transformations. Error bars are smaller than the symbols.

Table 3. Cation exchange selectivities of the basal surfaces and anhydrous interlayers predicted by our TI calculations. The third column corresponds to the replacement of all interlayer K ions; the fourth column corresponds to the replacement of a small number of $\mathrm{K}$ ions $(<3 \%)$ dispersed in the three interlayers. Confidence intervals are reported as $\pm 2 \sigma$.

\begin{tabular}{llll} 
Site type & Basal & Interlayer (entire) & Interlayer (trace) \\
\hline \hline $\log K_{\mathrm{eq}}{ }^{\mathrm{Na} / \mathrm{Cs}}$ & $-0.1 \pm 0.1$ & $2.2 \pm 0.1$ & $1.1 \pm 0.1$ \\
$\log K_{\mathrm{eq}} \mathrm{K} / \mathrm{Cs}$ & $-0.4 \pm 0.1$ & $-0.7 \pm 0.1$ & $-2.9 \pm 0.1$ \\
\hline
\end{tabular}

Our TI simulations predict that Na-Cs exchange on illite basal surfaces is essentially non-selective. This result is consistent with the ion exchange isotherm shown 
in Fig. 7a and confirms that our $50 \mathrm{~ns}$ MD simulations with mixed $\mathrm{NaCl}-\mathrm{CsCl}$

electrolytes were sufficiently long to probe equilibrium adsorption on the basal surfaces. As noted above, the non-selective nature of $\mathrm{Na}-\mathrm{Cs}$ exchange on illite basal surfaces is likely an artifact related to the unphysical relaxation of the siloxane surface cavities predicted by the CLAYFF model. The use of a rigid mineral structure in simulations of ion adsorption on the basal surface of mica (unpublished) resulted in a decreased tendency of $\mathrm{Na}^{+}$ions to drop deeply within the hexagonal cavities, a better agreement with X-ray reflectivity data, and less affinity of Na for the basal surfaces $\left(\log K_{\mathrm{eq}}{ }^{\mathrm{Na} / \mathrm{Cs}} \sim 2\right)$.

The results shown in Table 3 indicate that the anhydrous interlayer nanopores have a high selectivity for weakly hydrated cations (K, Cs). The predicted value of log $K_{\mathrm{ex}}{ }^{\mathrm{Na} / \mathrm{Cs}}$ in anhydrous interlayers is lower than obtained by DFT simulations of mica at $300 \mathrm{~K}\left[\log K_{\mathrm{eq}}{ }^{\mathrm{Na} / \mathrm{Cs}} \approx 4.0(\right.$ Suehara \& Yamada, 2013)] and lower than the values reported for the high affinity sites (Table 1). The difference is consistent with the unphysical relaxation of surface ditrigonal cavities in our MD simulations causing a significant overestimation of the affinity of $\mathrm{Na}$ for the external basal surfaces. Our simulations predict that adsorption in the interlayers has very little selectivity between $\mathrm{K}$ and $\mathrm{Cs}$, in agreement with DFT calculations (Okumura et al., 2013; Suehara \& Yamada, 2013). For example, DFT simulations of mica at $300 \mathrm{~K}$ yielded Helmholz free energies of exchange consistent with $\log K_{\mathrm{eq}}{ }^{\mathrm{K} / \mathrm{Cs}} \approx-0.6$ (Suehara \& Yamada, 2013) a value essentially equal to our prediction. Our results demonstrate for the first time that the specific affinity of interlayer sites for $\mathrm{K}$ ions relative to other alkaline metals of smaller and larger size is in essence a "Goldilocks" effect, indicating that the $\mathrm{K}^{+}$ion has an optimal size to 
accommodate these sites. This effect explains why $\mathrm{K}$ concentration in soils is a good predictor of the abundance of illitic clay minerals.

Finally, our TI calculations provide evidence of a strong driving force for cation segregation in collapsed illite interlayers: K-Cs exchange has little selectivity if the entire population of interlayer cations is transformed from $\mathrm{K}$ to $\mathrm{Cs}$, but it is highly unfavorable (by $16.4 \pm 0.7 \mathrm{~kJ} \mathrm{~mol}^{-1}$ ) if only a few $\mathrm{K}$ ions are exchanged for Cs in an otherwise $\mathrm{K}$ filled interlayer. This strong selectivity difference likely derives from the fact that, during replacement of the interlayer population of interlayer cations, the collapsed interlayer adjusts its basal spacing to accommodate the size of the interlayer cations. If only a few $\mathrm{K}$ ions are replaced by $\mathrm{Cs}$ in an otherwise K-filled interlayer, the large population of interlayer $\mathrm{K}$ ions imposes a basal spacing that is too small to comfortably accommodate Cs.

\subsection{Ion exchange kinetics on basal and edge surfaces}

Molecular dynamics simulation results were used to investigate the kinetics of ion exchange at basal and edge surface sites using a waiting time distribution technique analogous to a 1D jump diffusion model (Bourg \& Sposito, 2011b; Marry et al., 2008). Over the course of these simulations, no ions migrated from the bulk solution to the interlayer or within the interlayer itself due to significant energetic barriers to interlayer ion exchange. The dynamics of interlayer ion exchange will be the subject of future work. We determined the amount of time that $\mathrm{Na}$ and Cs ISSC reside in the vicinity of each individual site type (basal, H-, and I-) to compare element- and site-specific exchange dynamics. Positions of high affinity $\mathrm{Na}$ and $\mathrm{Cs}$ sorption sites were identified using 
density maps integrated over the entire simulation time. Geometries of inner-sphere edge sites differed from those of basal sites, so exchange events at these sites were calculated in a slightly different way. Ions were assumed to have left (or entered) an edge site when crossing out of (or into) a cylindrical zone with $2 \AA$ radius surrounding the Cs or Na site, a sufficiently large size to encompass edge ISSC. Ion exchange events involving a hop along the edge were not counted. Basal surface ion exchange events were counted when an ion left or entered a slab within $3 \AA ̊$ of the closest-approaching $\mathrm{Na}^{+}$ions, which approximately separates inner- and outer-sphere surface complexes for both $\mathrm{Cs}$ and $\mathrm{Na}$ (Fig. 4a). For each type of site, we calculated the distribution of ion residence times between exchange events (Fig. 9), as well as the time within which $90 \%$ of the $\mathrm{Na}$ or Cs ions leave the site (Table 4 ). We refer to the latter quantity as $\tau_{90}$. This approach enables us to directly compare the ion exchange fluxes between sites for both $\mathrm{Na}$ and Cs.
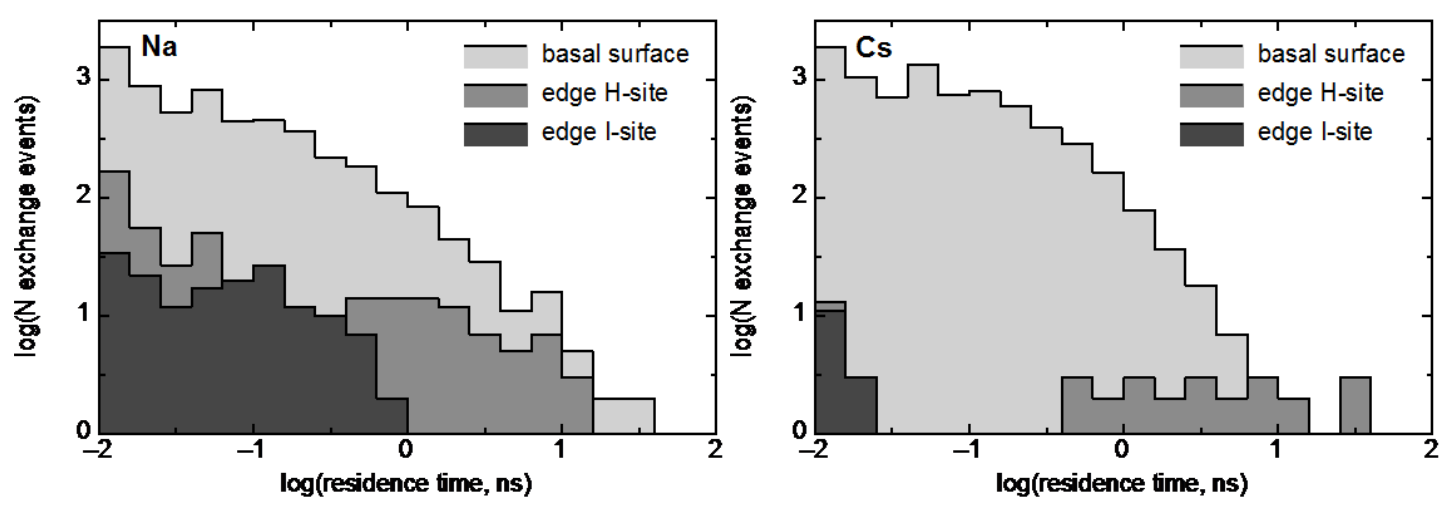

Figure 9. Histogram of $\mathrm{Na}$ (left) and $\mathrm{Cs}$ (right) residence times at edge and basal sites. Exchange dynamics of $\mathrm{Cs}$ at edge $\mathrm{H}$-sites are highly skewed towards long (>ns) residence times compared with the fast-exchanging $\mathrm{Na}$.

Table 4. Average timescales over which $90 \%$ of inner-sphere complexed ions exchanged with outer-sphere or diffuse swarm ions. Reported values are averaged over all ten simulations with different $\mathrm{Na} / \mathrm{Cs}$ ratios. Confidence intervals are reported as $\pm 2 \sigma$. 


\begin{tabular}{ccc|ccc}
\hline $\begin{array}{c}\tau_{90} \text { basal } \\
(\mathbf{n s})\end{array}$ & $\begin{array}{c}\tau_{90} \text { edge } \\
\text { H-site }(\mathbf{n s})\end{array}$ & $\begin{array}{c}\tau_{\text {90 }} \text { edge I- } \\
\text { site }(\mathbf{n s})\end{array}$ & $\begin{array}{c}\tau_{90} \text { basal } \\
(\mathbf{n s})\end{array}$ & $\begin{array}{c}\tau_{90} \text { edge } \\
\text { H-site }(\mathbf{n s})\end{array}$ & $\begin{array}{c}\tau_{90} \text { edge I- } \\
\text { site (ns) }\end{array}$ \\
\hline $0.30 \pm 0.03$ & $0.82 \pm 0.47$ & $0.22 \pm 0.07$ & $0.34 \pm 0.03$ & $7.25 \pm 2.34$ & $2.93 \pm 2.83$ \\
\hline
\end{tabular}

The typical distribution of ion residence times included a high probability of exchange over short timescales (i.e., many transient visits to the site) and a low probability of exchange over long timescales, on order of the duration of the entire simulations (i.e., few prolonged visits to the site). An example histogram of residence times is plotted for $\mathrm{Na}$ and $\mathrm{Cs}$ on basal surfaces and edge $\mathrm{H}$ - and I-sites for the $x_{\mathrm{Cs}}=0.5$ simulation in Fig. 9. The $\tau_{90}$ values for each ion and site type averaged over all ten simulations are listed in Table 4. On average, $\mathrm{Na}$ and $\mathrm{Cs} \tau_{90}$ residence times on the basal surfaces are within error of one another at $0.30 \pm 0.03 \mathrm{~ns}$ and $0.34 \pm 0.03 \mathrm{~ns}$, respectively. In contrast, the average $\tau_{90}$ value of Cs ions at edge $\mathrm{H}$-sites $(7.25 \pm 2.34 \mathrm{~ns})$ is considerably longer than that of $\mathrm{Na}$ ions at the same sites $(0.82 \pm 0.47 \mathrm{~ns})$. The same may be true for edge I-sites $(2.93 \pm 2.83 \mathrm{~ns}$ for $\mathrm{Cs}$ and $0.22 \pm 0.07 \mathrm{~ns}$ for $\mathrm{Na})$ except that the large errors for Cs make the values nominally equal. The results shown in Table 4 indicate that Cs binding at edge sites, in addition to being thermodynamically favored, is considerably more stable than for $\mathrm{Na}$. The results also confirm the necessity of simulating several tens of nanoseconds to reach complete exchange equilibrium with respect to Cs at edge $\mathrm{H}$-sites. The much poorer statistics for edge compared to basal sites arises from the fact that there are many more available basal sorption sites in each simulation.

\section{CONCLuSIONS}

Molecular dynamics simulations of a new fully-flexible illite structure displaying edge, basal, and interlayer sites give $\mathrm{Na} / \mathrm{Cs}$ sorption selectivities broadly consistent with the range of existing experimental data. Cesium sorbed to the exterior surfaces of illite 
form primarily ISSC at both basal and edge sites, while both $\mathrm{Na}$ and $\mathrm{Cs}$ form ISSC on basal surface sites adjacent to ditrigonal cavities on the siloxane surface, similar to existing X-ray reflectivity data. Ion exchange proceeds relatively rapidly for both $\mathrm{Na}$ and Cs at basal sites, in stark contrast with the slow exchange dynamics of Cs at edge sites, indicating a source of the high affinity for Cs at edges. Interlayer ions were found to be non-exchangeable over the timescale of the MD simulations reported here (50 ns), so thermodynamic integration calculations were performed instead to investigate the affinity of Cs for interlayer sites. These TI calculations demonstrate that complete K/Cs exchange in the interlayer sites is weakly selective and that there is a strong thermodynamic preference for Cs relative to $\mathrm{Na}$ in anhydrous interlayers. Exchange of trace interlayer $\mathrm{K}$ for Cs is highly unfavorable compared with complete replacement of $\mathrm{K}$ for Cs, revealing a strong driving force for interlayer ion stratification upon migration of Cs to slow sites. Together, these findings suggest that previously identified slow sites are likely located in the interlayers of micaceous clays, as hypothesized. The kinetics of interlayer ion exchange are not possible to resolve in these $50 \mathrm{~ns}$ MD simulations and will be the subject of a future study.

Geochemical modeling of the simulated adsorption and selectivity data reveals a fundamentally different ion adsorption behavior at edge and basal adsorption sites that had not previously been resolved, because of the difficulty of isolating these sites experimentally. In particular, adsorption at edge sites is shown to be non-ideal due to the impact of high Cs concentrations on edge site capacities, and edge sites are Cs selective at low Cs loadings. We conclude that the flexible model presented here is a substantive advance on existing models as it enables simultaneous investigation of molecular-level 
mechanisms governing ion exchange on various sites, including edge sites. Future studies will make use of this structure, which also allows for edge expansion, to specifically address the mechanisms of high-affinity frayed edge site formation. Alternative simulation techniques including metadynamics will be useful to elucidate the thermodynamics and mechanisms of frayed edge site formation.

Acknowledgements. The authors gratefully acknowledge support for this research from the Japan Atomic Energy Agency (JAEA)-LBNL Collaboration on Repository Geoscience and PA Technology Development. IB was partly supported by the Office of Science, Office of Basic Energy Sciences of the US Department of Energy under Contract DE-AC02-05CH11231. The MD and TI simulations reported in this paper were carried out using resources of the National Energy Research Scientific Computing Center (NERSC), which is supported by the Office of Science of the US Department of Energy under Contract DE-AC02-05CH11231. The DFT simulations were carried out using the SGI ICE X supercomputer at the Japan Atomic Energy Agency. GS was supported by funds allocated through his appointment as Chancellor's Professor, Emeritus, University of California, Berkeley. 


\section{References}

Anderson S. J. and Sposito G. (1991) Cesium-adsorption method for measuring accessible structural surface charge. Soil Sci. Soc. Am. J. 55, 1569-1576.

Åqvist J. (1990) Ion-water interaction potentials derived from free energy perturbation simulations. J. Phys. Chem. 94, 8021-8024.

Baeyens B. and Bradbury M. H. (2004) Cation exchange capacity measurements on illite using the sodium and cesium isotope dilution technique: Effects of the index cation, electrolyte concentration and competition: Modeling, Clays Clay Miner. 52, 421-431.

Becke, A.D. (1988) Density-functional exchange-energy approximation with correct asymptotic behavior. Phys. Rev. A 38, 3098.

Benedicto A., Missana T. and Fernández A. M. (2014) Interlayer collapse affects on cesium adsorption onto illite. Environ. Sci. Technol. 48, 4909-4915.

Berendsen H. J. C., Grigera J. R. and Straatsma T. P. (1987) The missing term in effective pair potentials. J. Phys. Chem. 91, 6269-6271.

Bergaoui L., Lambert J. F. and Prost R. (2005) Cesium adsorption on soil clay: macroscopic and spectroscopic measurements. Appl. Clay Sci. 29, 23-29.

Bickmore B. R., Rosso K. M., Nagy K. L., Cygan R. T. and Tadanier C. J. (2003) Ab initio determination of edge surface structures for dioctahedral 2:1 phyllosilicates: Implications for acid-base reactivity. Clays Clay Miner. 51, 359-371.

Bostick B. C., Vairavamurthy M. A., Karthikeyan K. G. and Chorover J. (2002) Cesium adsorption on clay minerals: An EXAFS spectroscopic investigation. Environ. Sci. Technol. 36, 2670-2676.

Bourg I. C., Sposito G. and Bourg A. C. M. (2007) Modeling the acid-base surface chemistry of montmorillonite. J. Colloid Interface Sci. 312, 297-310.

Bourg I. C. and Sposito G. (2010) Connecting the molecular scale to the continuum scale for diffusion processes in smectite-rich porous media. Environ. Sci. Technol. 44, 2085-2091.

Bourg I. C. and Sposito G. (2011a) Ion exchange phenomena. In Handbook of Soil Science, Properties and Processes, $2^{\text {nd }}$ ed. (eds. P. M. Huang, Y. Li and M. E. Sumner) CRC Press, Chapter 16.

Bourg I. C. and Sposito G. (2011b) Molecular dynamics simulations of the electrical double layer on smectite surfaces contacting concentrated mixed electrolyte $(\mathrm{NaCl}-$ $\mathrm{CaCl}_{2}$ ) solutions. J. Colloid Interface Sci. 360, 701-715.

Bourg I. C. and Steefel C. I. (2012) Molecular dynamics simulations of water structure and diffusion in silica nanopores. J. Phys. Chem. C 116, 1156-11564.

Bradbury M. H. and Baeyens B. (2000) A generalised sorption model for the concentration dependent uptake of caesium by argillaceous rocks. J. Contam. Hydrol. 42, 141-163.

Brouwer E., Baeyens B., Maes A. and Cremers A. (1983) Cesium and rubidium ion equilibria in illite clay. J. Phys. Chem. 87, 1213-1219.

Carroll S. A. and Walther J. V. (1990) Kaolinite dissolution at $25^{\circ}, 60^{\circ}$, and $80^{\circ} \mathrm{C} . \mathrm{Am} . \mathrm{J}$. Sci. 290, 797-810. 
Chen Z., Montavon G., Ribet S., Guo Z., Robinet J. C., David K., Tournassat C., Grambow B. and Landesman C. (2014) Key factors to understand in-situ behavior of Cs in Callovo-Oxfordian clay-rock (France). Chem. Geol. 387, 47-58.

Chorover J., DiChiaro M. and Chadwick O. (1999) Structural charge and cesium retention in a chronosequence of tephritic soils. Soil Sci. Soc. Am. J. 63, 169-177.

Churakov S. V. (2006) Ab initio study of sorption on pyrophyllite: Structure and acidity of the edge sites. J. Phys. Chem. B 110, 4135-4146.

Comans R. N. J., Middelburg J. J., Zonderhuis J., Woittiez J. R. W., De Lange G. J., Das H. A. and Van Der Weijden C. H. (1989) Mobilization of radiocaesium in pore water of lake sediments. Nature 339, 367-369.

Comans R. N. J., Haller M. and De Preter P. (1991) Sorption of cesium on illite: Nonequilibrium behaviour and reversibility. Geochim. Cosmochim. Acta 55, 433-440.

Comans R. N. J. and Hockley D. E. (1992) Kinetics of cesium sorption on illite, Geochim. Cosmochim. Acta 56, 1157-1164.

Cygan R. T., Liang J.-J. and Kalinichev A. G. (2004) Molecular models of hydroxide, oxyhydroxide, and clay phases and the development of a general force field. J. Phys. Chem. B 108, 1255-1266.

Dang L.X. (1995) Mechanism and thermodynamics of ion selectivity in aqueous solutions of 18-crown-6 ether: A molecular dynamics study. J. Am. Chem. Soc. 177, 6954-6960.

de Koning A. and Comans R. N. J. (2004) Reversibility of radiocaesium sorption on illite. Geochim. Cosmochim. Acta 68, 2815-2823.

Dzene L., Tertre E., Hubert F. and Ferrage E. (2015) Nature of the sites involved in the process of cesium desorption from vermiculite. J. Colloid Interface Sci. 455, 254-260.

Eberl D. D. (1980) Alkali cation selectivity and fixation by clay minerals. Clays Clay Miner. 28, 161-172.

Evans D. W., Alberts J. J., Clark R. A. III (1983) Reversible ion-exchange fixation of cesium-137 leading to mobilization from reservoir sediments. Geochim. Cosmochim. Acta 47, 1041-1049.

Fan Q. H., Tanaka M., Tanaka K., Sakaguchi A. and Takahashi Y. (2014) An EXAFS study on the effect of natural organic matter and the expandability of clay minerals on cesium adsorption and mobility. Geochim. Cosmochim. Acta 135, 49-65.

Ferrage E., Sakharov B. A., Michot L. J., Delville A., Bauer A., Lanson B., Grangeon S., Frapper G., Jiménez-Ruiz M. and Cuello G. J. (2011) Hydration properties and interlayer organization of water and ions in synthetic Na-smectite with tetrahedral layer charge. Part 2. Toward a precise coupling between molecular simulations and diffraction data. J. Phys. Chem. C 115, 1867-1881.

Filipovic-Vincekovic N., Barisic D., Masic N., Lulic S. (1991) Distribution of fallout radionuclides through soil surface layer. J. Radioan. Nucl. Ch. Ar. 148, 53-62.

Frenkel D. and Smit B. (2002) Understanding Molecular Simulation. Academic Press. 
Fuller A. J., Shaw S., Peacock C. L., Trivedi D., Small J. S., Abrahamsen L. G., Burke J. T. (2014) Ionic strength and $\mathrm{pH}$ dependent multi-site sorption of Cs onto a micaceous aquifer sediment. Appl. Geochem. 40, 32-42.

Fuller A. J., Shaw S., Ward M. B., Haigh S. J., Mosselmans J. F. W., Peacock C. L., Stackhouse S., Dent A. J., Trivedi D. and Burke I. T. (2015) Caesium incorporation and retention in illite interlayers. Appl. Clay Sci. 108, 128-134.

Gaboreau S., Claret F., Crouzet C., Giffaut E. and Tournassat C. (2012) Caesium uptake by Callovian-Oxfordian clayrock under alkaline perturbation. Appl. Geochem. 27, 1194-1201.

Grimme, S., Antony, J., Ehrlich, S., and Krieg, S. (2010) A consistent and accurate ab initio parametrization of density functional dispersion correction (dft-d) for the 94 elements H-Pu', J. Chem. Phys. 132, 154104.

Gualtieri A. (2000) Accuracy of XRPD QPA using the combined Rietveld-RIR method. J. Appl. Cryst. 33. 267-278.

Hayes K. F. and Leckie J. O. (1987) Modeling ionic strength effects on cation adsorption at hydrous oxide/solution interfaces. J. Colloid Interface Sci. 115, 564-572.

Hiemstra T. and Van Riemsdijk W. H. (1996) A surface structural approach to ion adsorption: The charge distribution (CD) model. J. Colloid Interface Sci. 179, 488508.

Hinton T., Kaplan D., Knox A., Coughlin D., Nascimento R., Watson S., Fletcher D. and Koo B.-J. (2006). Use of illite clay for in situ remediation of ${ }^{137} \mathrm{Cs}$-contaminated water bodies: Field demonstration of reduced biological uptake. Environ. Sci. Technol. 40, 4500-4505. DOI 10.1021/es060124x.

Holmboe M. and Bourg I. C. (2014) Molecular dynamics simulations of water and sodium diffusion in smectite interlayer nanopores as a function of pore size and temperature. J. Phys. Chem. C 118, 1001-1013.

Honda M., Shimoyama I., Okamoto Y., Baba Y., Suzuki S. and Yaita T. (2016) X-ray absorption fine structure at the cesium $\mathrm{L}_{3}$ absorption edge for cesium sorbed in clay minerals. J. Phys. Chem. C 120, 5534-5538.

Hsiao Y.-W. and Hedström M. (2015) Molecular dynamics simulations of $\mathrm{NaCl}$ permeation in bihydrated montmorillonite interlayer nanopores. J. Phys. Chem. C 119, 17352-17361.

Ikeda T., Suzuki S. and Yaita T. (2015) Characterization of adsorbed alkali metal ions in 2:1 type clay minerals from first-principles metadynamics. J. Phys. Chem. A 119, 8369-8375.

Karnland O., Olsson S., Nilsson U. and Sellin P. (2007) Experimentally determined swelling pressures and geochemical interactions of compacted Wyoming bentonite with highly alkaline solutions. Phys. Chem. Earth 32, 275-286.

Kim Y. and Kirkpatrick R. J. (1998) NMR $T_{1}$ relaxation study of ${ }^{133} \mathrm{Cs}$ and ${ }^{23} \mathrm{Na}$ adsorbed on illite. Amer. Mineral. 83, 661-665. 
Kogure T., Morimoto K., Tamura K., Sato H. and Yamagishi A. (2012) XRD and HRTEM evidence for fixation of cesium ions in vermiculite clay. Chem. Lett. 41, 380-382.

Kresse, G. and Furthmüller, J. (1996b) Efficient iterative schemes for ab initio totalenergy calculations using a plane-wave basis set. Phys. Rev. B 54, 11169-11186.

Kresse, G. and Hafner, J. (1994) Ab initio molecular dynamics for liquid metals. Phys. Rev. B 47, 558-561.

Kresse, G. and Hafner, J. (1993) Ab initio molecular-dynamics simulation of the liquidmetal-amorphous-semiconductor transition in germanium. Phys. Rev. B 49, 1425114269.

Kresse, G. and Joubert, D. (1999) From ultrasoft pseudopotentials to the projector augmented-wave method. Phys. Rev. B 59, 1758-1775.

Kulik D. A., Vinograd V. L., Paulsen N. and Winkler B. (2010) (Ca,Sr)CO3 aqueoussolid solution systems: from atomistic simulations to thermodynamic modeling. Phys. Chem. Earth 35, 217-232.

Kwon K. D. and Newton A. G. (2016). Structure and stability of pyrophyllite edge surfaces: Effect of temperature and water chemical potential. Geochim. Cosmochim. Acta, in review.

Lavikainen L. P., Hirvi J. T., Kasa S., Schatz T. and Pakkanen T. A. (2015) Stability of dioctahedral 2:1 phyllosilicate edge structures based on pyrophyllite models. Theor. Chem. Acc. 134, 112.

Lee, C., Yang, W. and Parr, R. G. (1988) Development of the Colle-Salvetti correlationenergy formula into a functional of the electron density. Phys. Rev. B 37, 785.

Lee S. S., Fenter P., Park C., Sturchio N. C., Nagy K. L. (2010) Hydrated cation speciation at the muscovite (001)-water interface. Langmuir 26, 16647-16651.

Lee S. S., Fenter P., Nagy K. L. and Sturchio N. C. (2012) Monovalent ion adsorption at the muscovite (001)-solution interface: Relationships among ion coverage and speciation, interfacial water structure, and substrate relaxation. Langmuir 28, 86378650.

Liu C., Zachara J. M., Smith S. C., McKinley J. P. and Ainsworth C. C. (2003) Desorption kinetics of radiocesium from subsurface sediments at Hanford Site, USA. Geochim. Cosmochim. Acta 67, 2893-2912.

Liu C., Zachara J. M. and Smith S. C. (2004) A cation exchange model to describe $\mathrm{Cs}^{+}$ sorption at high ionic strength in subsurface sediments at Hanford site, USA. $J$. Contam. Hydrol. 68, 217-238.

Liu X., Chen J., Sprik M., Lu X., Wang R. (2014) Surface acidity of 2:1-type dioctahedral clay minerals from first principles molecular dynamics simulations. Geochim. Cosmochim. Acta 140, 410-417.

Marcus Y. (1991) Thermodynamics of solvation of ions. Part 5. Gibbs free energy of hydration at 298.15 K. J. Chem. Soc. Faraday Trans. 87, 2995-2999. 
Marry V., Rotenberg B. and Turq P. (2008) Structure and dynamics of water at a clay surface from molecular dynamics simulation. Phys. Chem. Chem. Phys. 10, 48024813.

Marry V., Dubois E., Malikova N., Durand-Vidal S., Longeville S. and Breu J. (2011) Water dynamics in hectorite clays: Influence of temperature studied by coupling neutron spin echo and molecular dynamics. Environ. Sci. Technol. 45, 2850-2855.

Martins D. M. S., Molinari M., Gonçalves M. A., Mirão J. P. and Parker S. C. (2014) Toward modeling clay mineral nanoparticles: The edge surfaces of pyrophyllite and their interaction with water. J. Phys. Chem. C 118, 27308-26317.

McCombie C. (1997) Nuclear waste management worldwide, Physics Today 50, 56-62.

McKinley J. P., Zeissler C. J., Zachara J. M., Serne R. J., Lindstrom R. M., Schaef H. T., Orr R. D. (2001) Distribution and retention of ${ }^{137} \mathrm{Cs}$ in sediments at the Hanford Site, Washington. Environ. Sci. Technol. 35, 3433-3441.

McKinley J. P., Zachara J. M., Heald S. M., Dohnalkova A., Newville M. G. and Sutton S. R. (2004) Microscale distribution of cesium sorbed to biotite and muscovite. Environ. Sci. Technol. 38, 1017-1023.

Mukai H., Hatta T., Kitazawa H., Yamada H., Yaita T. and Kogure T. (2014) Speciation of radioactive soil particles in the Fukushima contaminated area by IP autoradiography and microanalyses. Environ. Sci. Technol. 48, 13053-13059.

Nakano M., Kawamura K. and Ichikawa Y. (2003) Local structural information of Cs in smectite hydrates by means of an EXAFS study and molecular dynamics simulations. Appl. Clay Sci. 23, 15-23.

Nakao A., Ogasawara S., Sano O., Ito T. and Yanai J. (2014) Radiocesium sorption in relation to clay mineralogy of paddy soils in Fukushima, Japan. Sci. Tot. Environ. 468-469, 523-529.

Newton A. G. and Sposito G. (2015) Molecular dynamics simulations of pyrophyllite edge surfaces: Structure, surface energies, and solvent accessibility. Clays Clay Miner. 63, 278-290.

Newton A. G., Kwon K. D. and Cheong D.-K. (2016) Edge structure of montmorillonite from atomistic simulations. Minerals 6, 25.

Okumura M., Nakamura H. and Machida M. (2013) Mechanism of strong affinity of clay minerals to radioactive cesium: First-principles calculation study for adsorption of cesium at frayed edge sites in muscovite. J. Phys. Soc. Japan 82, 033802.

Okumura T. Tamura K., Fujii E., Yamada H. and Kogure T. (2014) Direct observation of cesium at the interlayer region in phlogopite mica. Microscopy 63(1), 65-72. doi: 10.1093/jmicro/dft045.

Olsen C. R., Lowry P. D., Lee S. Y., Larsen I. L. and Cutshall N. H. (1986) Geochemical and environmental processes affecting radionuclide migration from a formerly used seepage trench. Geochim. Cosmochim. Acta 50, 593-607.

Pacala S. and Socolow R. (2004) Stabilization wedges: Solving the climate problem for the next 50 years with current technologies. Science 305, 968-972. 
Pestana L.R., Kolluri K., Head-Gordon T. and Lammers L. (in review) Direct exchange mechanism for interlayer ions in non-swelling clays.

Plimpton S. (1995) Fast parallel algorithms for short-range molecular dynamics. $J$. Comput. Phys. 117, 1-42.

Poinssot C., Baeyens B. and Bradbury M. H. (1999) Experimental and modelling studies of caesium sorption on illite. Geochim. Cosmochim. Acta 63, 3217-3227.

Predota M., Zhang Z., Fenter P., Wesolowski D. J., Cummings P.T. (2004) Electric double layer at the rutile (110) surface. 2. Adsorption of ions from molecular dynamics and X-ray experiments. J. Phys. Chem. B 108, 12061-12072.

Rajec P., Sucha V., Eberl D. D., Srodon J. and Elsass F. (1999) Effect of illite particle shape on cesium sorption. Clays Clay Miner. 47, 755-760.

Ridley M. K., Hiemstra T., van Riemsdijk W. H., Machesky (2009) Inner-sphere complexation of cations at the rutile-water interface: A concise surface structural interpretation with the CD and MUSIC model. Geochim. Cosmochim. Acta 73, 18411856.

Rotenberg B., Marry V., Vuilleumier R., Malikova N., Simon C. and Turq P. (2007) Water and ions in clays: Unraveling the interlayer/micropore exchange using molecular dynamics. Geochim. Cosmochim. Acta 71, 5089-5101.

Rotenberg B., Morel J.-P., Marry V., Turq P. and Morel-Desrosiers N. (2009) On the driving force of cation exchange in clays: Insights from combined microcalorimetry experiments and molecular simulation. Geochim. Cosmochim. Acta 73, 4034-4044.

Ryckaert, J.-P., Ciccotti G., and Berendsen H. J. C. (1977) Numerical integration of the cartesian equations of motion of a system with constraints: molecular dynamics of nalkanes. J. Comput. Phys. 23, 327.

Sainz-Díaz C. I., Cuadros J. and Hernández-Laguna A. (2001) Analysis of cation distribution in the octahedral sheet of dioctahedral 2:1 phyllosilicates by using inverse Monte Carlo methods. Phys. Chem. Miner. 28, 445-454.

Sakuma H. and Kawamura K. (2011) Structure and dynamics of water on $\mathrm{Li}^{+}-, \mathrm{Na}^{+}-, \mathrm{K}^{+}-$, $\mathrm{Cs}^{+}-, \mathrm{H}_{3} \mathrm{O}^{+}$-exchanged muscovite surfaces: A molecular dynamics study. Geochim. Cosmochim. Acta 75, 63-81.

Sawhney B. L. (1972) Selective sorption and fixation of cations by clay minerals: A review. Clays Clay Miner. 20, 93-100.

Shiozawa S. (2014) Vertical migration of radiocesium in soil in Fukushima. In: Agricultural Implications of the Fukushima Nuclear Accident. DOI 10.1007/978-4431-54328-2_6.

Skelton A. A., Fenter P., Kubicki J. D., Wesolowski D. J. and Cummings P. T. (2011) Simulations of the quartz (10̄11)/water interface: A comparison of classical force fields, ab initio molecular dynamics, and X-ray reflectivity experiments. J. Phys. Chem. C 115, 2076-2088.

Slade P. G., Quirk J. P. and Norrish K. (1991) Crystalline swelling of smectite samples in concentrated $\mathrm{NaCl}$ solutions in relation to layer charge. Clays Clay Miner. 39, 234238. 
Smith J. T. and Comans R. N. J. (1996) Modelling the diffusive transport and remobilisation of ${ }^{137} \mathrm{Cs}$ in sediments: The effects of sorption kinetics and reversibility. Geochim. Cosmochim. Acta 60, 995-1004.

Smith D. E. and Dang L. X. (1994) Computer simulations of $\mathrm{NaCl}$ association in polarizable water. J. Chem. Phys. 100, 3757-3766,

Sposito G. (2004) The Surface Chemistry of Natural Particles, Oxford University Press.

Sposito G. (2008) The Chemistry of Soils, Oxford University Press.

Staunton S. and Roubaud M. (1997) Adsorption of ${ }^{137} \mathrm{Cs}$ on montmorillonite and illite: Effect of charge compensating cation, ionic strength, concentration of Cs, $\mathrm{K}$ and fulvic acid. Clays Clay Miner. 45, 251-260.

Steefel C. I., Carroll S., Zhao P. and Roberts S. (2003) Cesium migration in Hanford sediment: a multisite cation exchange model based on laboratory transport experiments. J. Contam. Hydrol. 67, 219-246.

Straatsma T. P., Berendsen H. J. C. and Postma J. P. M. (1986) Free energy of hydrophobic hydration: A molecular dynamics study of noble gases in water. $J$. Chem. Phys. 85, 6720-6727.

Suehara S. and Yamada H. (2013) Cesium stability in a typical mica structure in dry and wet environments from first-principles. Geochim. Cosmochim. Acta 109, 62-73.

Tachi Y., Yotsuji K., Seida Y. and Yui M. (2011) Diffusion and sorption of $\mathrm{Cs}^{+}, \mathrm{I}^{-}$and HTO in samples of the argillaceous Wakkanai Formation from the Horonobe URL, Japan: Clay-based modeling approach. Geochim. Cosmochim. Acta 75, 6742-6759.

Tamura K., Kogure T., Watanabe Y., Nagai C., and Yamada H. (2014) Uptake of cesium and strontium ions by artificially altered phlogopite. Environ. Sci. Technol. 48, 58085815.

Tamura T. (1961) Cesium sorption reactions as indicator of clay mineral structures. Clays Clay Miner. 10, 389-398.

Teppen B. J. and Miller D. M. (2006) Hydration energy determines isovalent cation exchange selectivity by clay minerals. Soil Sci. Soc. Am. J. 70, 31-40.

Tournassat C., Ferrage E., Poinsignon C. and Charlet L. (2004) The titration of clay minerals II. Structure-based model and implications for clay reactivity. J. Colloid Interface Sci. 273, 234-246.

Tournassat C., Bourg I. C., Holmboe M., Sposito G. and Steefel C. I. (2016) Molecular dynamics simulations of anion exclusion in clay interlayer nanopores. Clays Clay Miner., in press.

Turner N. B., Ryan J. N. and Saiers J. E. (2006) Effect of desorption kinetics on colloidfacilitated transport of contaminants: Cesium, strontium, and illite colloids. Water Resour. Res. 42, W12S09.

Wampler J. M., Krogstad E. J., Elliott W. C., Kahn B. and Kaplan D. I. (2012) Long-term selective retention of natural $\mathrm{Cs}$ and $\mathrm{Rb}$ by highly weathered coastal plain soils. Environ. Sci. Technol. 46, 3837-3843.

White G. N. and Zelazny L. W. (1988) Analysis and implications of the edge structure of dioctahedral phyllosilicates. Clays Clay Miner. 36, 141-146. 
Yasunari T., Stohl A., Hayano R., Burkhart J. Eckhardt S. and Yasunari T. (2011) Cesium-137 deposition and contamination of Japnese soils due to the Fukushima nuclear accident. Proc. Nat. Acad. Sci. 108, 49. DOI 10.1073/pnas.1112058108.

Yoshida N. and Kanda J. (2012) Tracking the Fukushima radionuclides. Science 336, 1115. DOI 10.1126/science.1219493.

Zachara J. M., Smith S. C., Liu C., McKinley J. P., Serne R. J. and Gassman P. L. (2002) Sorption of $\mathrm{Cs}^{+}$to micaceous subsurface sediments from the Hanford site, USA. Geochim. Cosmochim. Acta 66, 193-211.

Zaunbrecher L. K., Cygan R. T., Elliott W. C. (2015) Molecular models of cesium and rubidium adsorption on weathered micaceous minerals. J. Phys. Chem. A 119, 56915700 . 


\section{Figure Captions}

Figure 1. Schematic view of the illite AC edge surface before protonation of edge $O$ atoms. Colors indicate $\mathrm{O}$ (red), $\mathrm{H}$ (pink), $\mathrm{Al}$ (light blue), $\mathrm{Si}$ (dark blue), and $\mathrm{K}$ atoms (purple). In the absence of isomorphic substitutions, the edge surface carries two silanol sites (Oe1, Oe2), one aluminol site (Oe3), and one bridging oxygen (Oe6). The different edge $\mathrm{O}$ atoms are labeled on the figure. Isomorphic substitutions of $\mathrm{Al}$ for $\mathrm{Si}$ near the edge surface give rise to additional types of edge $\mathrm{O}$ atoms, listed in parentheses. Brackets indicate regions of the edge surface referred to hereafter as hanging $(\mathrm{H})$ and indented $(\mathrm{I})$.

Figure 2. Molecular dynamics simulation snapshot at the end of a $50 \mathrm{~ns}$ production run. Water molecules and $\mathrm{Na}, \mathrm{Cs}$, and $\mathrm{Cl}$ ions are not shown. Edge oxygen atoms are colored for ease of differentiation: $\equiv \mathrm{Al}_{\mathrm{O}}-\mathrm{OH}_{2}$ oxygens (Oe3) are in green; $\equiv \mathrm{Si}-\mathrm{OH}$ and $\equiv \mathrm{Al}_{\mathrm{T}}-\mathrm{OH}$ oxygens $(\mathrm{Oe} 1, \mathrm{Oe} 2, \mathrm{Oe} 4$, Oe 5$)$ are in yellow; $\equiv \mathrm{Si}-\mathrm{O}-\mathrm{Al}_{\mathrm{O}} \equiv$ and $\equiv \mathrm{Al}_{\mathrm{T}}-\mathrm{O}-\mathrm{Al}_{\mathrm{O}} \equiv$ oxygens (Oe6, Oe7) are in black. Other colors are as in Fig. 1.

Figure 3. Map of Cs density averaged over the entire $50 \mathrm{~ns}$ simulation with $x_{\mathrm{Cs}}=0.5$. Cesium primarily binds to ditrigonal cavities on the basal surfaces and to "cleaved cavities" at edge surface H-sites.

Figure 4. Density profiles of solutes $(\mathrm{Na}, \mathrm{Cs}$, and $\mathrm{Cl})$ and water oxygen atoms $(\mathrm{Ow})$ adjacent to illite basal surfaces during our $50 \mathrm{~ns}$ simulations at $x_{C s}=0.9$ (a) and $x_{C s}=0.1$ (b). Distances $(z)$ are reported relative to the distance where all solute and solvent ion concentrations go to zero.

Figure 5. Density profiles of adsorbed ions adjacent to hanging (a) and indented (b) sites on the illite edge surface.

Figure 6. Adsorption isotherms for $\mathrm{Na}$ (blue diamonds) and $\mathrm{Cs}$ (red circles) determined from the ten 50 ns MD simulation runs on (a) basal surfaces and (b) edge H-sites. Isotherms were fitted using the thermodynamic model Eqs. 8-9. 
Figure 7. Na-Cs exchange isotherms for (a) basal and (b) edge sites. Basal exchange behavior is consistent with an ideal surface solution, while edges exhibit non-ideal exchange behavior. Edges are significantly Cs-selective at low Cs surface loadings but become increasingly Na-selective as the aqueous mole fraction of Cs approaches 1.0.

Figure 8. Thermodynamic integration (TI) prediction of the Gibbs free energy of cation exchange (relative to $\mathrm{Na}$ ) as a function of the Gibbs free energy of hydration (relative to $\mathrm{Na}$ ). The different colors show results obtained at three different sites on the illite surface: on the external basal surface (red), in collapsed interlayers where all interlayer ions are simultaneously transformed (blue), and in collapsed interlayers where most ions remain $\mathrm{K}^{+}$while a few dispersed ions are transformed (yellow). Large symbols show free energies obtained for $\mathrm{Na}, \mathrm{K}$, and $\mathrm{Cs}$ (from left to right); smaller symbols show the intermediate steps of the alchemical transformations. Error bars are smaller than the symbols.

Figure 9. Histogram of $\mathrm{Na}^{+}$(left) and $\mathrm{Cs}^{+}$(right) residence times at edge and basal sites. Exchange dynamics of $\mathrm{Cs}^{+}$at edge $\mathrm{H}$-sites are highly skewed towards long (nm) residence times compared with the fast-exchanging $\mathrm{Na}^{+}$. 


\section{Figures}

\section{Figure 1.}

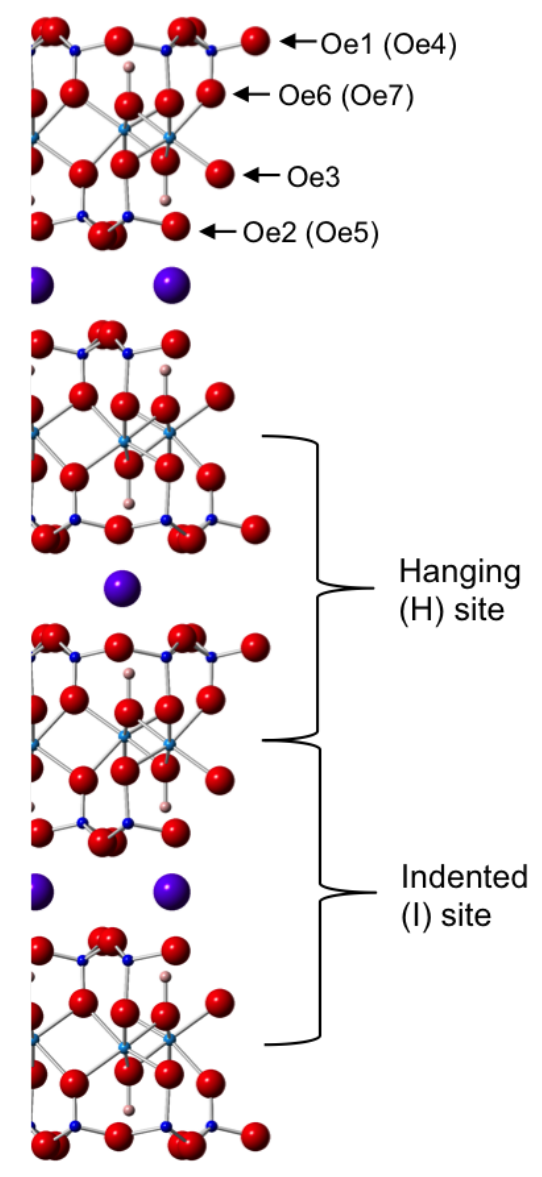


Figure 2.

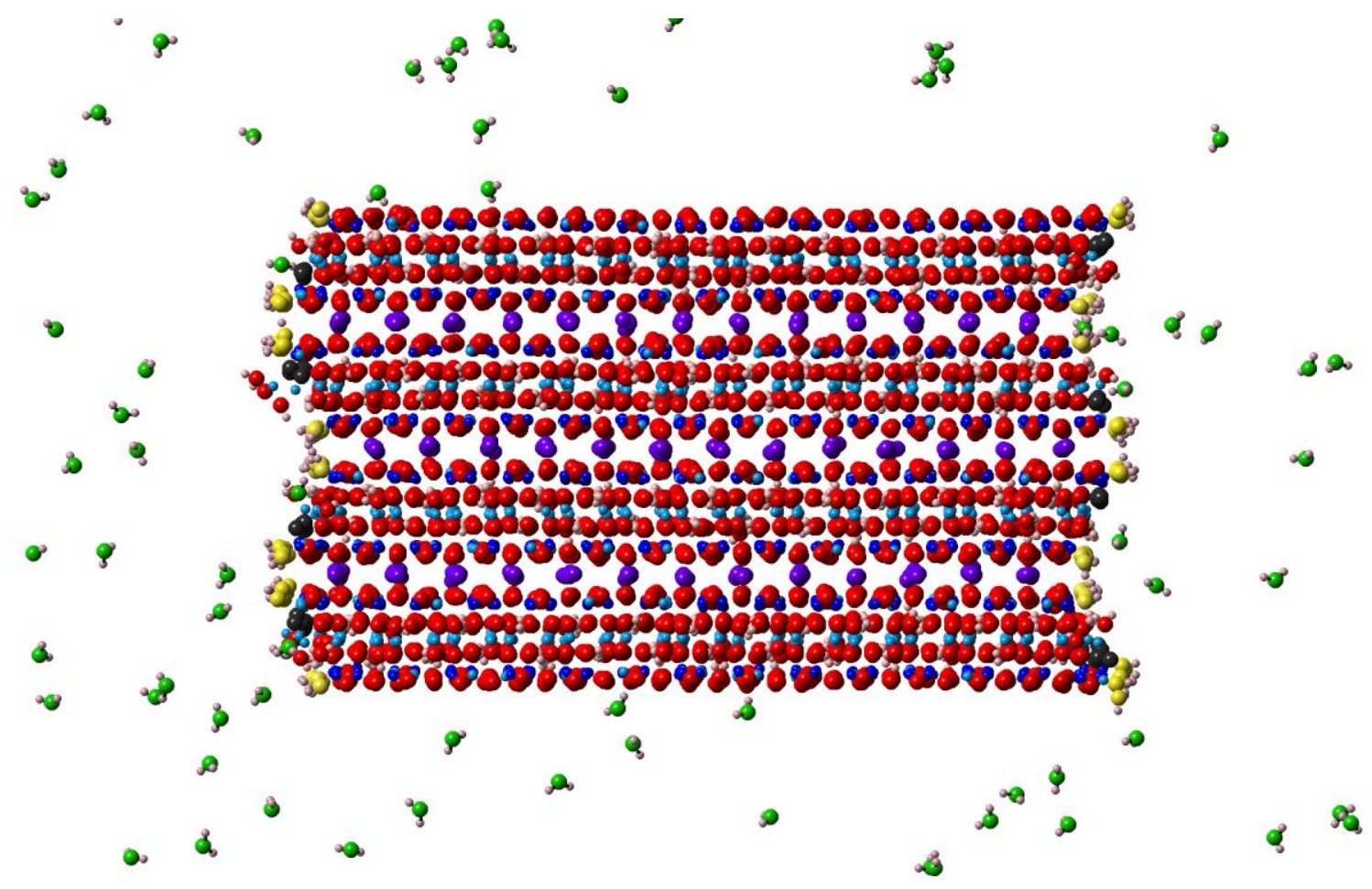


Figure 3.

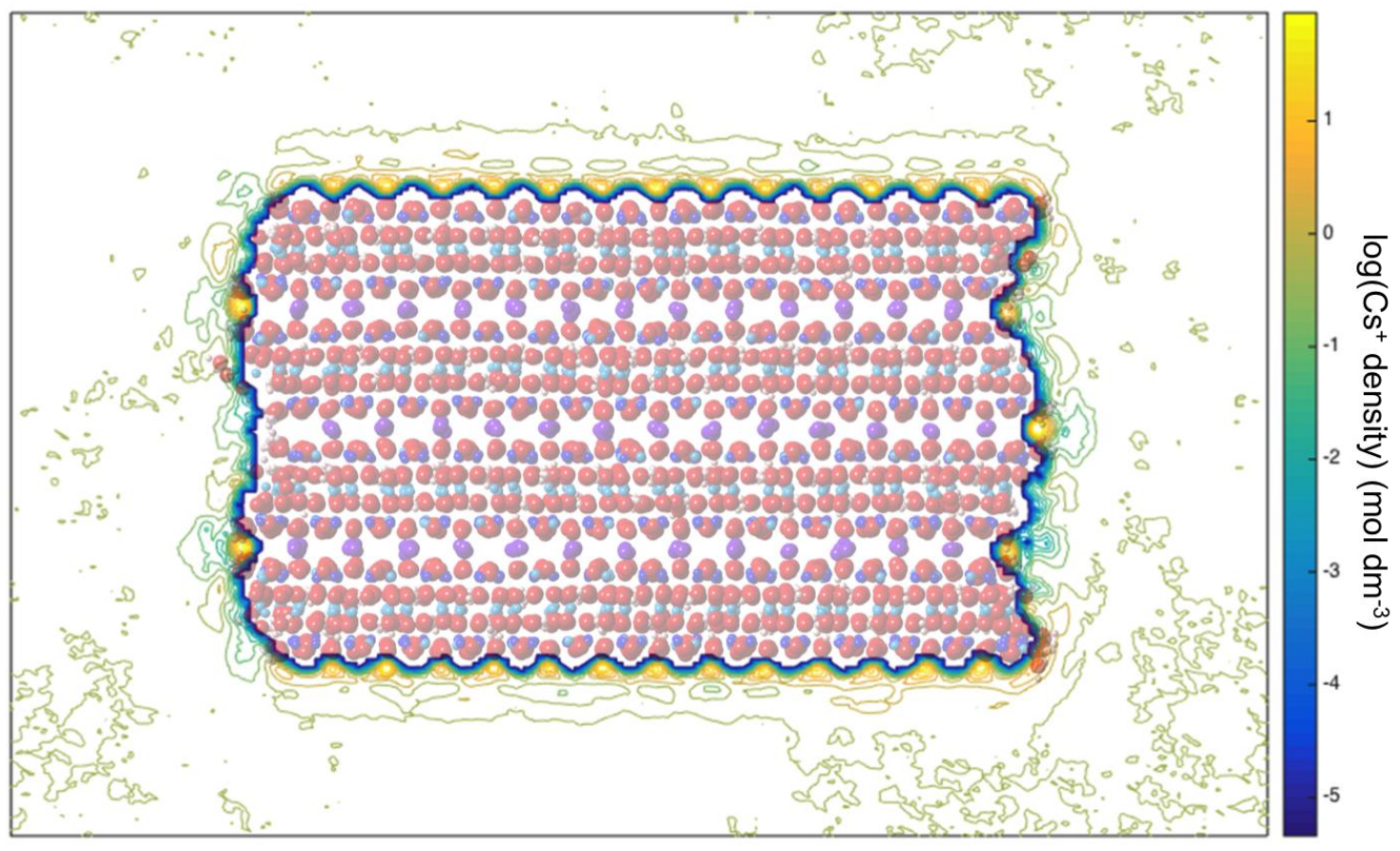


Figure 4.
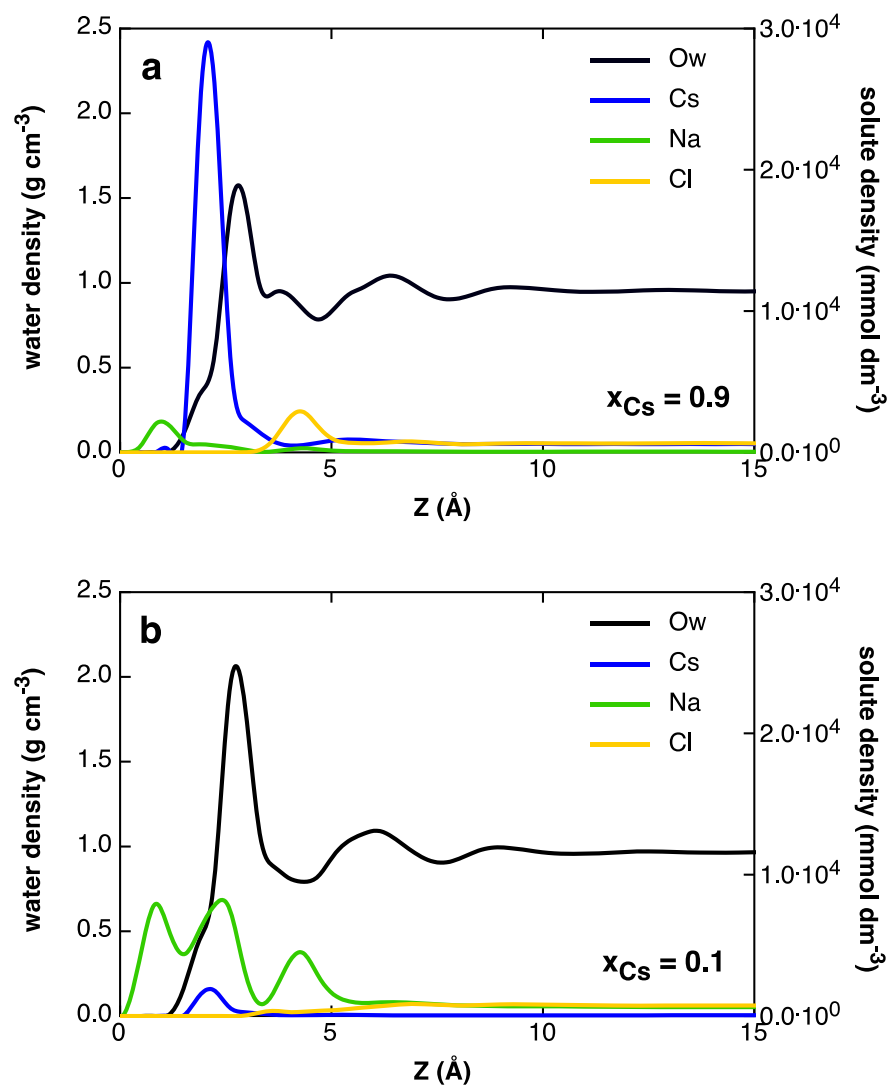
Figure 5.
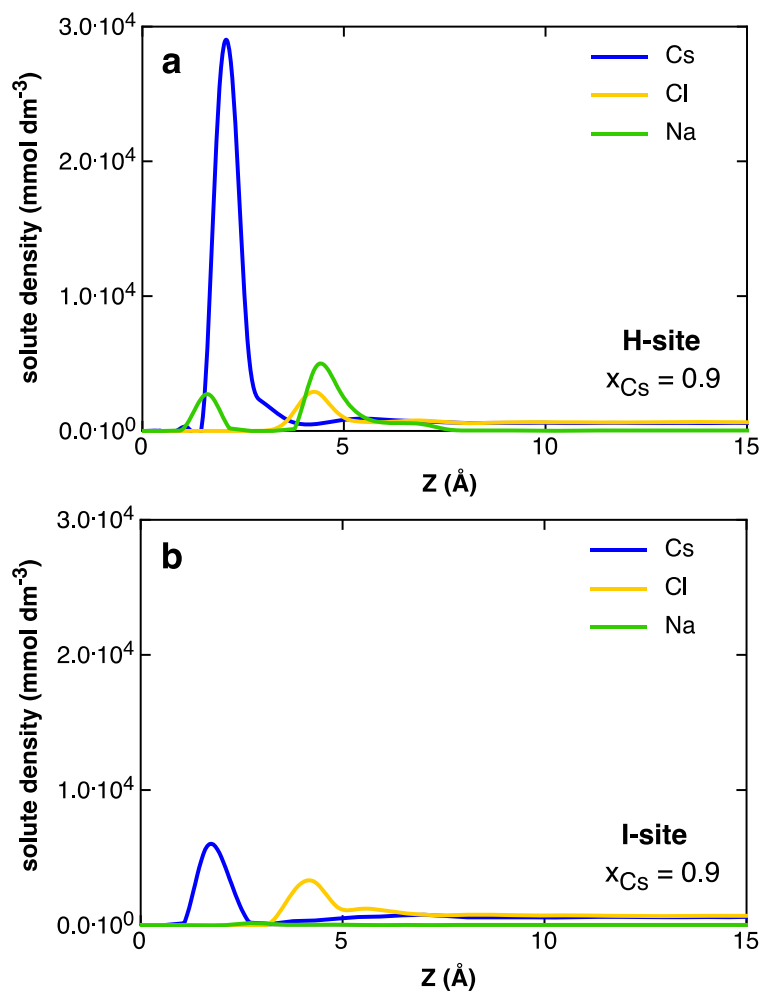


\section{Figure 6.}
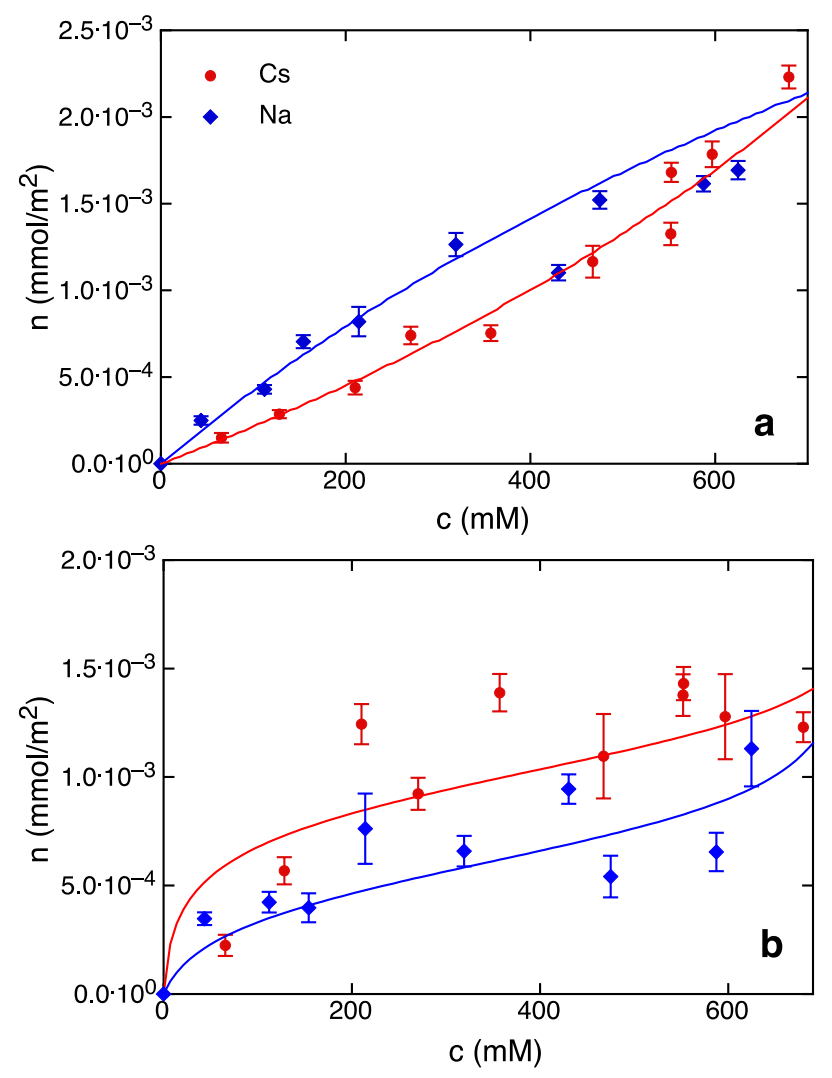
Figure 7.

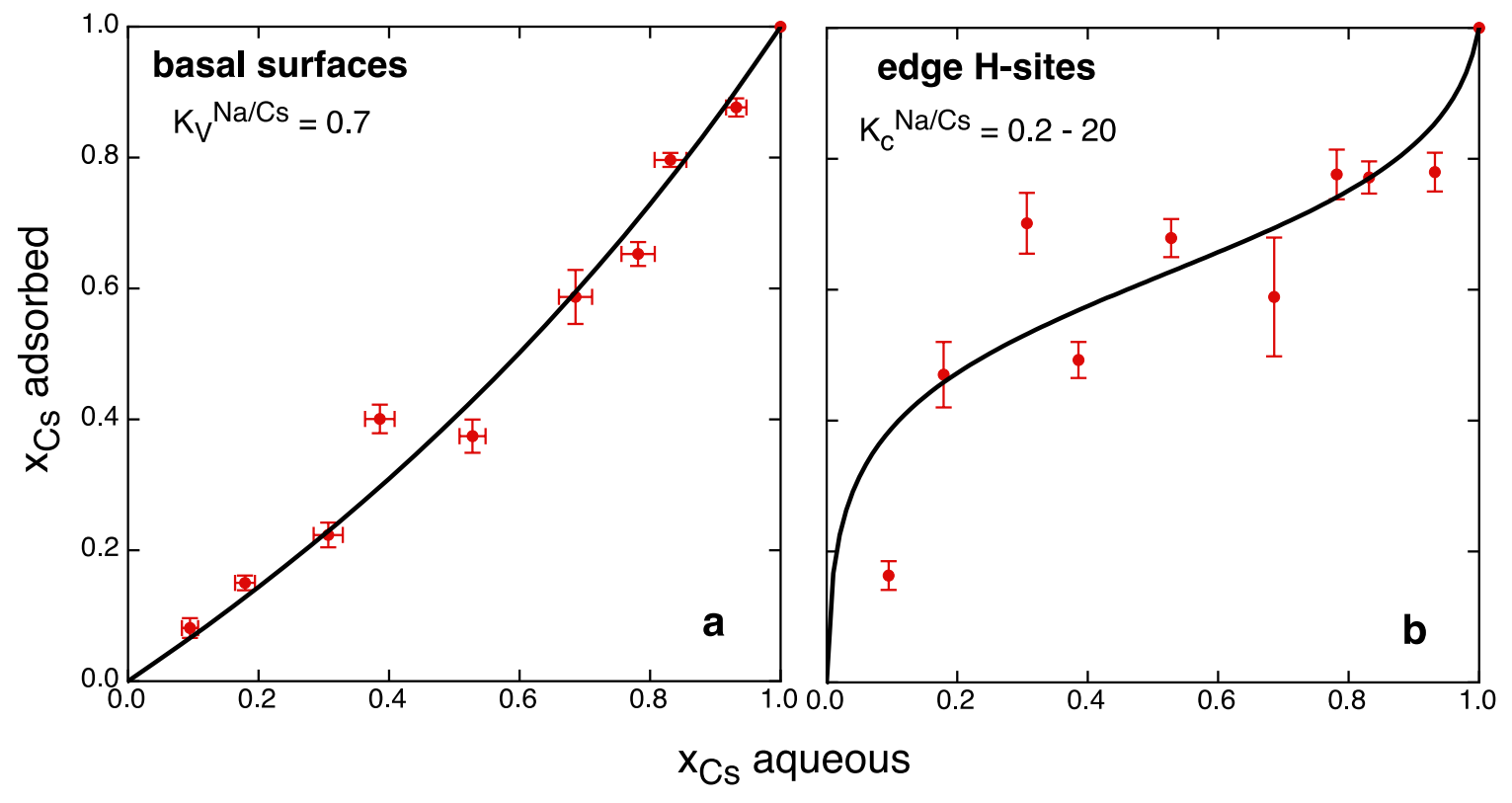


Figure 8.

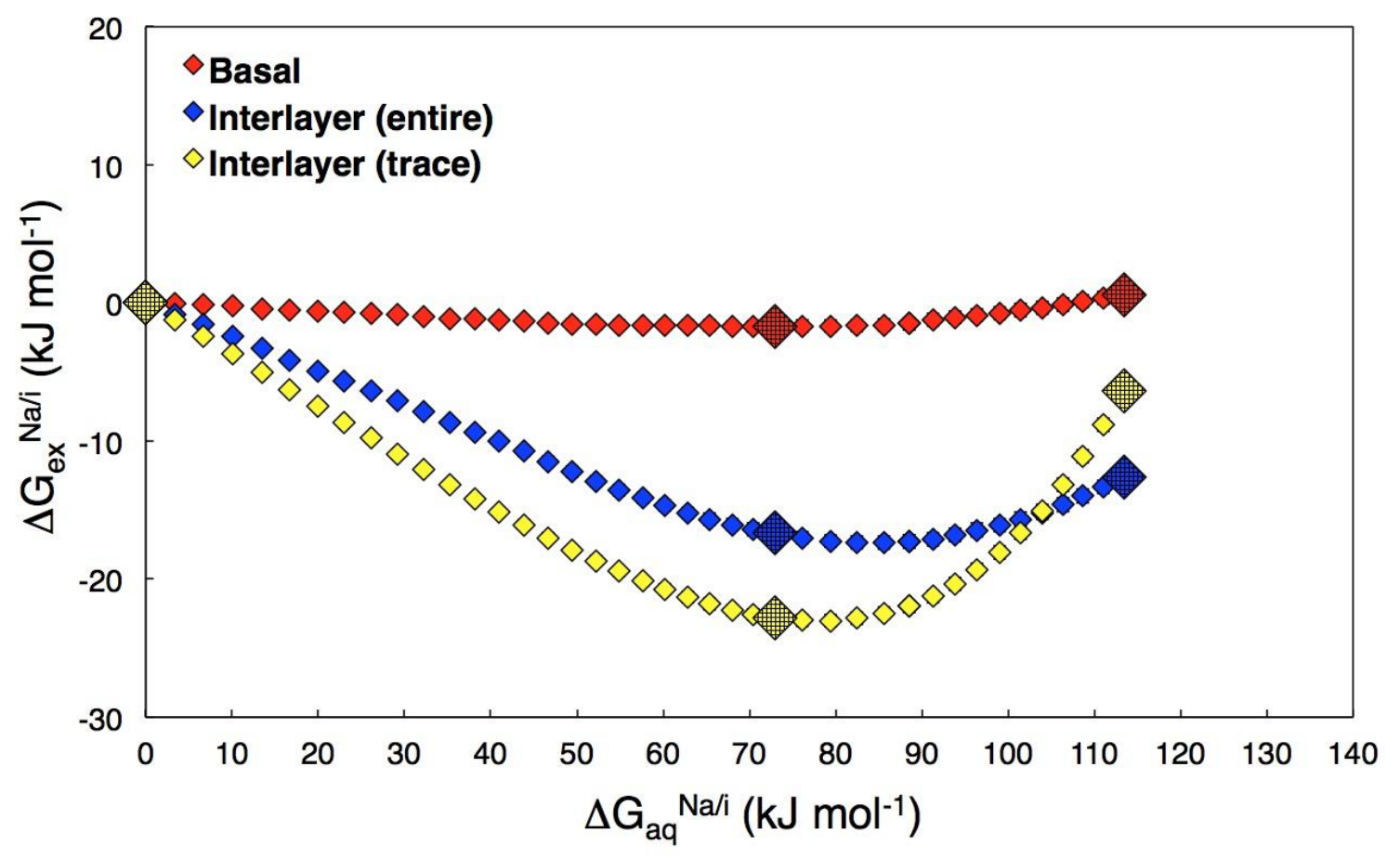


Figure 9.
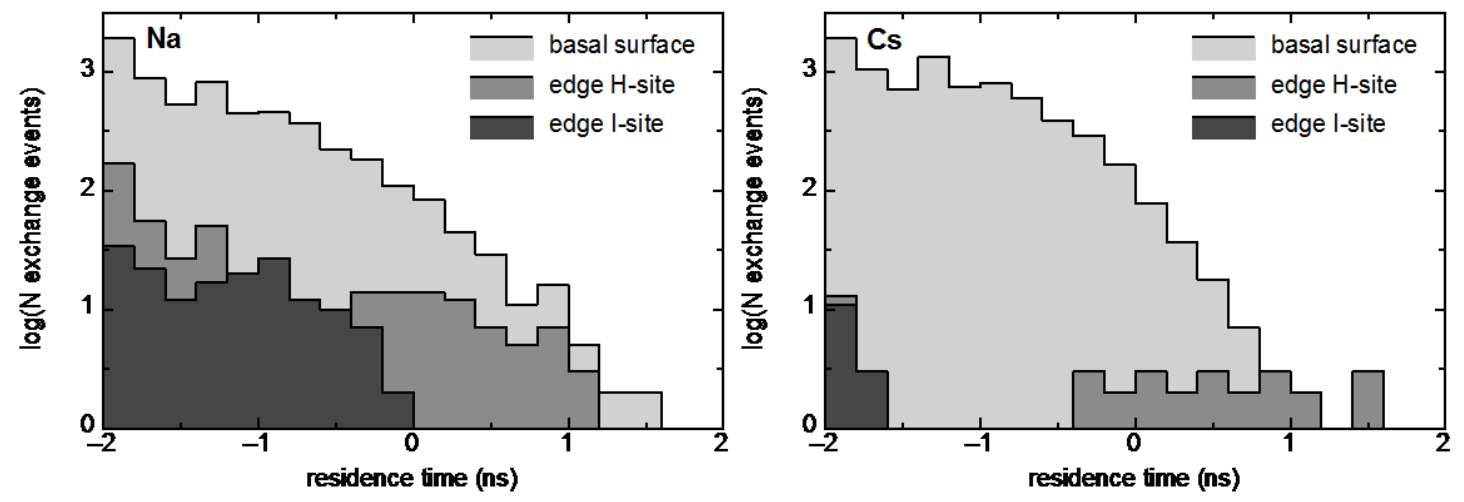


\section{Tables}

Table 1. Cation exchange selectivities of the high affinity and basal sites used in surface complexation models of Cs adsorption on illite and related minerals. Some models also include an intermediate affinity site of unclear mechanistic basis. The table shows the range of values used in existing models of illite surface chemistry (Brouwer et al., 1983; Poinssot et al., 1999; Bradbury and Baeyens, 2000; Steefel et al., 2003; Liu et al., 2004; Turner et al., 2006; Gaucher et al., 2009; Chen et al., 2014; Fuller et al., 2014; Benedicto et al., 2014; Fan et al., 2014). For comparison, values for smectite basal surfaces are shown in the last column as calculated by Bourg and Sposito (2011a) based on previous studies. Cesium exchange selectivity on smectite increases with layer charge (values are reported for smectite layer charges ranging from 0.7 to $1.4 \mathrm{~mol}_{\mathrm{c}} \mathrm{kg}^{-1}$ ). The notation $K_{\mathrm{eq}}{ }^{i / j}$ refers to the equilibrium constant for the replacement of $i$ by $j$ on illite surface sites.

\begin{tabular}{llll} 
Site type & Illite basal site & Illite high affinity site & Smectite basal site \\
\hline \hline $\log K_{\mathrm{eq}}{ }^{N a / C s}$ & 1.6 to 2.0 & 6.6 to 7.2 & 0.7 to 1.7 \\
$\log K_{\mathrm{eq}}{ }^{\mathrm{K} / \mathrm{Cs}}$ & 0.4 to 1.1 & 4.1 to 5.5 & 0.2 to 1.2 \\
\hline
\end{tabular}

Table 2. Partial charges and coordination state of edge $\mathrm{O}$ atoms. Other properties of edge $\mathrm{O}$ atoms are defined by the CLAYFF model. Octahedral and tetrahedral $\mathrm{Al}$ atoms are referred to as $\mathrm{Al}_{\mathrm{O}}$ and $\mathrm{Al}_{\mathrm{T}}$, respectively.

\begin{tabular}{|c|c|c|c|c|c|c|c|c|}
\hline \multirow[b]{2}{*}{$\begin{array}{l}\text { Edge } \\
\text { Site }\end{array}$} & \multirow[b]{2}{*}{ Site Description } & \multirow[b]{2}{*}{$\begin{array}{l}\text { Partial } \\
\text { Charge }\end{array}$} & \multirow[b]{2}{*}{ B.V. } & \multirow[b]{2}{*}{$\begin{array}{l}\text { Cation } \\
\text { Charge }\end{array}$} & \multicolumn{4}{|c|}{ \# Coordinating Cations } \\
\hline & & & & & $\mathbf{A l}_{\mathbf{O}}$ & $\begin{array}{r}(\Lambda \\
\mathbf{S i}\end{array}$ & $\mathbf{A l}_{\mathrm{T}}$ & H \\
\hline Oe1 & Hanging $\equiv \mathrm{Si}-\mathrm{OH}$ & -0.95000 & 2.00 & 0.95000 & - & 1 & - & 1 \\
\hline $\mathrm{Oe} 2$ & Indented $\equiv \mathrm{Si}-\mathrm{OH}$ & -0.95000 & 2.00 & 0.95000 & - & 1 & - & 1 \\
\hline Oe3 & Octahedral $\equiv \mathrm{Al}_{\mathrm{O}}-\mathrm{OH}_{2}$ & -0.84760 & 2.50 & 1.34760 & 1 & - & - & 2 \\
\hline Oe4 & Hanging $\equiv \mathrm{Al}_{\mathrm{T}}-\mathrm{OH}$ & -1.06875 & 1.75 & 0.81875 & - & - & 1 & 1 \\
\hline Oe5 & Indented $\equiv \mathrm{Al}_{\mathrm{T}}-\mathrm{OH}$ & -1.06875 & 1.75 & 0.81875 & - & - & 1 & 1 \\
\hline Oe6 & Bridging $\equiv \mathrm{Si}-\mathrm{O}-\mathrm{Al}_{\mathrm{O}} \equiv$ & -1.28750 & 1.50 & 0.78750 & 1 & 1 & - & - \\
\hline Oe7 & Bridging $\equiv \mathrm{Al}_{\mathrm{T}}-\mathrm{O}-\mathrm{Al}_{\mathrm{O}} \equiv$ & -1.40625 & 1.25 & 0.65625 & 1 & - & 1 & - \\
\hline $\mathrm{Al}_{\mathrm{O}}$ & Octahedral edge Al & 1.81250 & - & - & - & - & - & - \\
\hline
\end{tabular}


Table 3. Cation exchange selectivities of the basal surfaces and anhydrous interlayers predicted by our TI calculations. The third column corresponds to the replacement of all interlayer K ions; the fourth column corresponds to the replacement of a small number of $\mathrm{K}$ ions $(<3 \%)$ dispersed in the three interlayers. Confidence intervals are reported as $\pm 2 \sigma$.

\begin{tabular}{llll} 
Site type & Basal & Interlayer & Interlayer (trace) \\
\hline \hline $\log K_{\text {eq }}{ }^{\mathrm{Na} / C \mathrm{Cs}}$ & $-0.1 \pm 0.1$ & $2.2 \pm 0.1$ & $1.1 \pm 0.1$ \\
$\log K_{\text {eq }} \mathrm{K} / \mathrm{Cs}$ & $-0.4 \pm 0.1$ & $-0.7 \pm 0.1$ & $-2.9 \pm 0.1$ \\
\hline
\end{tabular}

Table 4. Average timescales over which $90 \%$ of inner-sphere complexed ions exchanged with outer-sphere or diffuse swarm ions. Reported values are averaged over all ten simulations with different $\mathrm{Na} / \mathrm{Cs}$ ratios. Confidence intervals are reported as $\pm 2 \sigma$.

\begin{tabular}{ccc|ccc}
\multicolumn{4}{c}{ Na } & \multicolumn{3}{c}{ Cs } \\
\hline $\begin{array}{c}\tau_{\text {90 }} \text { basal } \\
(\mathbf{n s})\end{array}$ & $\begin{array}{c}\tau_{\text {90 }} \text { edge } \\
\text { H-site (ns) }\end{array}$ & $\begin{array}{c}\tau_{\text {90 }} \text { edge I- } \\
\text { site (ns) }\end{array}$ & $\begin{array}{c}\tau_{\text {90 }} \text { basal } \\
(\mathbf{n s})\end{array}$ & $\begin{array}{c}\tau_{\text {90 }} \text { edge } \\
\text { H-site (ns) }\end{array}$ & $\begin{array}{c}\tau_{\text {90 }} \text { edge I- } \\
\text { site (ns) }\end{array}$ \\
\hline $0.30 \pm 0.03$ & $0.82 \pm 0.47$ & $0.22 \pm 0.07$ & $0.34 \pm 0.03$ & $7.25 \pm 2.34$ & $2.93 \pm 2.83$ \\
\hline
\end{tabular}




\section{Electronic Annex}

Density functional theory (DFT) methods. We evaluated the electronic structure of a muscovite (110)-edge using DFT-based calculations performed in the Vienna Ab initio Simulation Package (VASP; Kresse and Hafner, 1993; Kresse and Hafner, 1994; Kresse and Furthmüller, 1996a; Kresse and Furthmüller, 1996b), which supports the projector augmented wave (PAW; Blöchl, 1994; Kresse and Joubert, 1999) and generalized gradient approximations (GGA), among others. We use BLYP functional (Becke, 1988; Lee et al., 1988) with Grimm's van der Waals correction (Grimme et al., 2010). The cut-off energies in structural relaxation calculations are set to be $600 \mathrm{eV}$ and $5 \times 1 \times 3 \mathrm{k}$-point grids are taken in the relaxation. In all the calculations, the structural relaxation is repeated until all the forces on all atoms are below $0.02 \mathrm{eV} / \AA$. All the DFT calculations are executed the SGI ICE X supercomputer at the Japan Atomic Energy Agency.

We constructed a periodically replicated (110)-type edge structure for muscovite, with edges separated by $10 \AA$ of vacuum (Figure EA1). The lattice constants of the unit cell are provided in Table EA1. Charge density is evaluated for comparison with the Oe6and Oe3-Al chemical bonds. The charge density in the vicinity of Al, Oe3, and Oe6 atomic positions are shown in Figures EA2. The maximum electron density is $0.04 / \AA^{3}$ in these figures. Figure EA2c clearly shows a significant break in electron density in the AlOe3 bond.

Thermodynamic integration (TI) calculation methods. For our TI calculations, the size $\left(\sigma_{i}\right)$ and well-depth $\left(\varepsilon_{i}\right)$ parameters describing the Van der Waals interaction energy $\phi$ between two ions of type $i$ on the Lennard-Jones 6-12 interaction model $\left[\phi\left(r_{i}\right)=4 \varepsilon_{i}\right.$ 
$\left[\left(\sigma_{i} / r_{i}\right)^{12}-\left(\sigma_{i} / r_{i}\right)^{6}\right]$ were modified from the value for $\mathrm{K}$ to the value for Na or Cs were modified in a series of small steps. More precisely, we chose a thermodynamic path in which $\sigma(\lambda)=(1-\lambda) \times \sigma_{\mathrm{K}}+\lambda \times \sigma_{\text {final }}\left(\right.$ with $\sigma_{\text {final }}=\sigma_{\mathrm{Na}}$ or $\left.\sigma_{\mathrm{Cs}}\right)$ and $\lambda$ was incremented in 15 (K to $\mathrm{Cs}$ ) or 25 ( $\mathrm{K}$ to $\mathrm{Na}$ ) regular steps. The parameter $\varepsilon_{i}$ was not varied, because $\varepsilon_{\mathrm{Na}}=$ $\varepsilon_{\mathrm{K}}=\varepsilon_{\mathrm{Cs}}$ according to the Smith-Dang parameters for $\mathrm{Na}, \mathrm{K}, \mathrm{Cs}$, and $\mathrm{Cl}$ (Smith and Dang, 1994; Dang, 1995). Each small transformation step was followed by $2.5 \mathrm{~ns}$ of equilibration and $1.5 \mathrm{~ns}$ of simulation in the NPT ensemble. At each $\lambda$-value, 350 (for the ions in water) or 1100 to 1500 snapshots (for the ions on the clay surface) of the coordination of the ions of interest were used to calculate the ensemble average value of $\langle\partial \mathcal{H} / \partial \lambda\rangle_{\lambda}$, where $\mathcal{H}$ is the Hamiltonian. Finally, the Gibbs free energy difference for the transformation of $\mathrm{K}$ to Na or Cs was calculated as $\Delta G=\int_{0}^{1}\langle\partial \mathcal{H} / \partial \lambda\rangle_{\lambda} \mathrm{d} \lambda$.

Table EA1. Lattice constants of the (110)-edge system.

\begin{tabular}{cccccc}
$\mathrm{a}(\AA)$ & $\mathrm{b}(\AA)$ & $\mathrm{c}(\AA)$ & $\alpha$ (degrees) & $\beta$ (degrees) & $\gamma$ (degrees) \\
\hline 5.220 & 23.9759 & 10.2837 & 80.3973 & 95.8120 & 90.0791
\end{tabular}


(a)

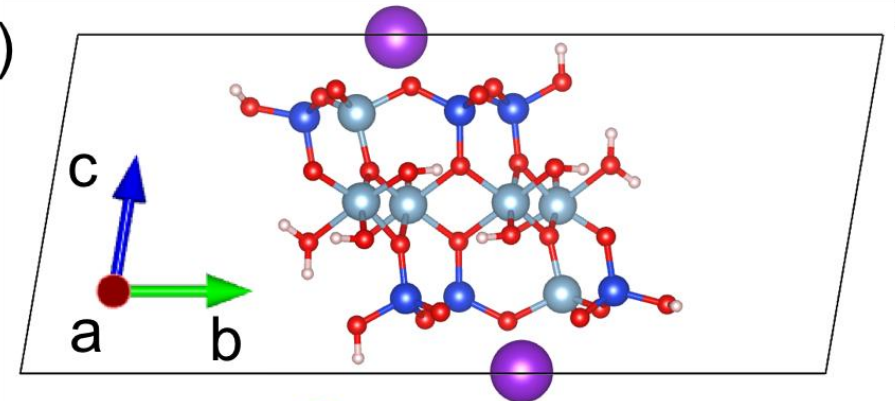

(b)

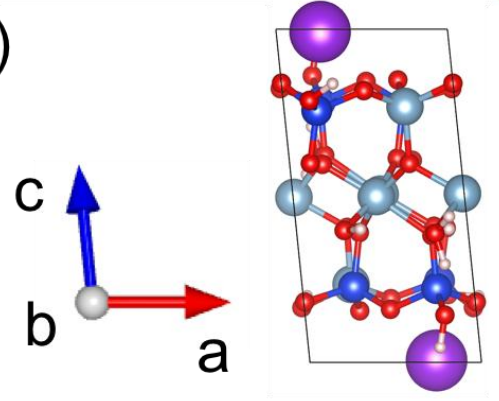

(c)

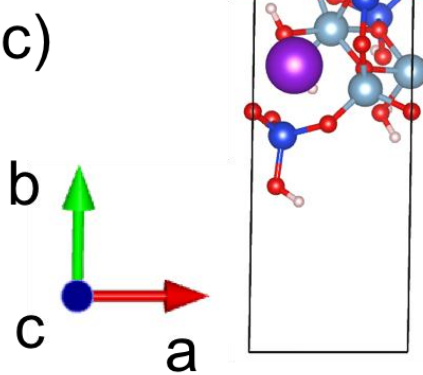

Figure EA1. Illustration of the (110)-edge structure of muscovite. Purple, silver, blue, red, and pink spheres represent potassium, aluminum, silicon, oxygen, and hydrogen atoms. Projected figure on (a) b-c (b) c-a and (c) a-b planes are shown. The width of the vacuum space in the b-axis direction is $10 \AA$. The lattice parameters are shown in Table EA1.
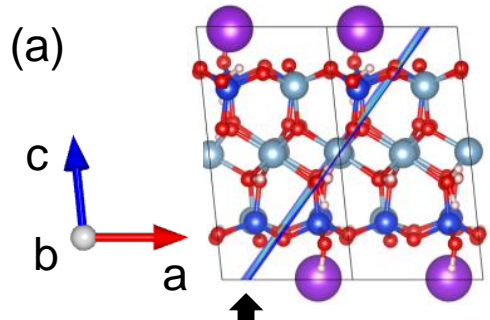

(c)

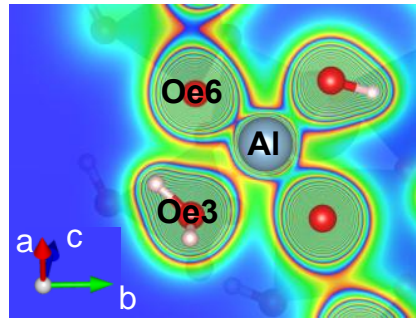

Section including $\mathrm{Al}, \mathrm{Oe} 3$, and $\mathrm{Oe} 6$

(b)

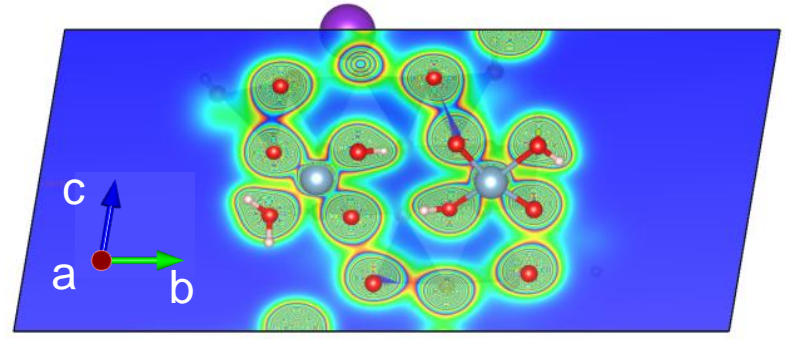

Figure EA2. Cross section (a) of the electron density distribution surrounding Al, Oe3, and Oe6 (b), with a maximum electron density of is $0.04 \AA^{-3}$. The electron density minimum separating doubly protonated Oe 3 is shown in greater detail in (c). 
Table EA2. Specific surface excess of $\mathrm{Cs}$ and $\mathrm{Na}$ on basal and edge sites, with 2 s.e. uncertainties. Edge $\mathrm{H}$ - and I- site surface excess values are normalized to the total edge area and basal values are normalized to the basal surface area. Basal surfaces and edge $\mathrm{H}$ sites accommodate the majority of cation sorption to illite exterior surfaces. Adsorption in the interlayers was not observed on the $50 \mathrm{~ns}$ time scale of our MD simulations.

\begin{tabular}{|c|c|c|c|c|c|c|c|c|}
\hline \multirow[b]{2}{*}{$x_{C s}$} & \multicolumn{4}{|c|}{$\mathbf{n}_{\mathrm{Cs}}^{\mathrm{w}}\left(\mu \mathrm{mol} \mathrm{m^{-2 }}\right)$} & \multicolumn{4}{|c|}{$\mathrm{n}_{\mathrm{Na}}^{\mathrm{w}}\left(\mu \mathrm{mol} \mathrm{m^{-2 }}\right)$} \\
\hline & basal & $\begin{array}{l}\text { edge } \mathrm{H} \text { - } \\
\text { site }\end{array}$ & $\begin{array}{l}\text { edge I- } \\
\text { site }\end{array}$ & $\begin{array}{l}\text { whole } \\
\text { particle }\end{array}$ & basal & $\begin{array}{l}\text { edge } H- \\
\text { site }\end{array}$ & $\begin{array}{l}\text { edge I- } \\
\text { site }\end{array}$ & $\begin{array}{l}\text { whole } \\
\text { particle }\end{array}$ \\
\hline 0.1 & $0.15(3)$ & $0.22(5)$ & $-0.03(2)$ & $0.34(5)$ & $1.69(14)$ & $1.13(17)$ & $0.25(6)$ & 2.91(5) \\
\hline 0.2 & $0.29(2)$ & $0.57(6)$ & $-0.01(4)$ & $0.69(6)$ & $1.62(12)$ & $0.65(9)$ & $0.05(8)$ & $2.41(4)$ \\
\hline 0.3 & $0.44(4)$ & $1.24(9)$ & $0.03(4)$ & $0.95(8)$ & $1.52(11)$ & $0.54(10)$ & $-0.09(7)$ & $2.32(5)$ \\
\hline 0.4 & $0.74(5)$ & $0.92(7)$ & $-0.04(4)$ & $1.31(11)$ & $1.10(8)$ & $0.94(7)$ & $0.05(8)$ & $1.86(4)$ \\
\hline 0.5 & $0.75(5)$ & $1.39(9)$ & $0.01(9)$ & $1.57(9)$ & $1.26(7)$ & $0.66(7)$ & $-0.09(9)$ & $1.72(7)$ \\
\hline 0.6 & $1.17(9)$ & $1.10(19)$ & $-0.32(11)$ & $1.71(10)$ & $0.82(12)$ & $0.76(16)$ & $0.24(6)$ & $1.55(8)$ \\
\hline 0.7 & $1.33(6)$ & $1.38(10)$ & $-0.23(11)$ & $1.94(11)$ & $0.70(13)$ & $0.40(7)$ & $0.14(11)$ & $1.16(4)$ \\
\hline 0.8 & $1.68(6)$ & $1.43(8)$ & $-0.04(8)$ & $2.61(16)$ & $0.43(8)$ & $0.42(5)$ & $0.016(5)$ & $0.73(3)$ \\
\hline 0.9 & $1.78(7)$ & $1.28(20)$ & $0.22(10)$ & $3.04(27)$ & $0.25(5)$ & $0.35(3)$ & $-0.01(5)$ & $0.41(2)$ \\
\hline 1.0 & $2.23(6)$ & $1.23(7)$ & $0.05(5)$ & $3.29(13)$ & $0.00(0)$ & $0.00(0)$ & $0.00(0)$ & $0.00(0)$ \\
\hline
\end{tabular}

